\title{
El Paleolítico Superior en la Meseta
}

\author{
Sergio Ripoll lópez ${ }^{*}$ Carmen Cacho Quesada** \\ Y LUCIANO J. MUNICIO GONZÁLEZ $Z^{* * *}$
}

RESUMEN

ABSTRACT

En el presente artículo se realiza una revisión de las evidencias arqueológicas

$y$ artísticas encuadrables en el Pleistoceno Superior Final de la Meseta castellana. La falta de información arqueológica que se tieen sobre este período es debida, más al escaso auge

y a la precariedad de resultados en la investigación sobre esta fase de la Prehistoria en nuestra región que a una realidad objetiva. La abundancia de yacimientos con arte correspondiente a este momento no puede realicionarse, con un vacío de referencias arqueológicas pero, todavía hoy, es muy dificil establecer sobre elementos materiales, y sobre todo, estatigráficos, el contexto cronológico y cultural en el que se produciría el desarrollo de los procesos artísticos del interior peninsular. De cualquier forma esperamos que en un futuro próximo se produzca un sustancial avance en el estudio de esta etapa en el área concreta.
In the present paper is accomplished a review of the archaeologic and artistic evidence during the Upper Pleistocene in the Castilian Plateau. The lack of archaeologic information that has on this period is had to, more to the scarce summit and to the results precariousness in the investigation on this phase of the Prehistory in our region than to an objective reality. The abundance of deposits with corresponding art to this moment can not be related, to an archaeologic references vacuum but, still today, it is very difficult to establish on material elements and, above all, stratigraphics, the chronological and cultural context in the one which would be produced the development of the artistic processes of the peninsular interior. In any way we wait that in a nex future is produced a substantial advance in the study of this stage in the concrete area.

* Departamento de Prehistoria e Historia Antigua. Facultad de Geografía e Historia. Universidad Nacional de Educación a Distancia. Avda. Senda del Rey, s/n. 28071 Madrid. Email: Sripoll@sr.uned.es.

** Museo Arqueológico Nacional. Serrano, 13. 28001 Madrid. Email: ccq@man.es.

*** Servicio Territorial de Educación y Cultura de Segovia. Junta de Castilla y León. Plaza de la Merced, 12.40003 Segovia. Email: m106337303@abonados.cplus.es. 


\section{LOS TESTIMONIOS ARQUEOLÓGICOS}

Hasta hace relativamente poco tiempo, la Meseta era considerada una región inhóspita, cuyas extremas condiciones climáticas la convertían en un lugar inhabitable durante gran parte del Pleistoceno Superior Final. A esta suposición contribuian los escasos vestigios de ocupación conocidos, ya que si prescindimos de algunas industrias atribuidas al Paleolítico Superior -el conjunto de Oña en Burgos (Ibero, J.M., 1923), algunas cavidades leonesas, como la cueva de la Cantera (Neira, A., y Mallo, F., 1990) - los asentamientos de las terrazas del Manzanares en Madrid (Pérez de Barradas, J., 1919, 1929, 1935) todas ellas de difícil contrastación científica en la actualidad, debido en parte a la desaparición de los yacimientos o incluso de las colecciones- el resto se reducía a algunas estaciones aisladas de arte rupestre, desprovistas de cualquier signo evidente de habitación, tal era el caso de la cueva de Penches (Hernández, E., 1917) y Ojo Guareña en Burgos (Uribarri, J. L., 1973), la cueva del Reguerillo en Madrid (Breuil, H., 1920; Loriana, M. de, 1942), o las cavidades de la Hoz y los Casares en Guadalajara (Cabré, J., 1934) (figura 1).

Sin embargo, el desarrollo de las investigaciones de estos últimos años en la región está aportando una serie de novedades que creemos importante recoger aquí. De esta manera, la localización de varios yacimientos con niveles de ocupación atestigua la habitabilidad de la Meseta durante el Paleolítico Superior muy especialmente durante sus fases finales.

En la Meseta Norte hay que destacar los recientes hallazgos realizados en el noreste de la provincia de León, la cueva de la Uña y el Espertín (Bernaldo de Quirós, F., y Neira, A., 1992), así como en el alto valle del Ebro, la cueva del Níspero (Burgos) (Corchón, Ma․S., 1989). En general, se trata de pequeños abrigos situados en zonas de alta y media montaña (entre los 1.000 y los $1.200 \mathrm{~m}$. de altitud), próximos a las vías de comunicación o lugares de paso natural, que permiten el acceso a la Cornisa Cantábrica. De la mayoría de estos sitios sólo existen algunos estudios preliminares que apuntan a una ocupación durante el Tardiglaciar e inicios del Holoceno.

Ya en la cuenca del Duero, en pleno páramo vallisoletano y sobre una terraza del río Pisuerga, nos encontramos con el yacimiento al aire libre del Palomar de Mucientes (Valladolid). Aquí se excavaron tres niveles de ocupación con una industria lítica abundante y, según los excavadores, homogénea. Precisamente uno de estos niveles fue interpretado como un suelo de cabaña con la presencia de dos hogares y un murete o alineamiento de piedras. Ha sido atribuido al Chatelperroniense por su paralelismo con el nivel 10 de Cueva Morín en Santander (Martín, E., et alii, 1986). Creemos, 


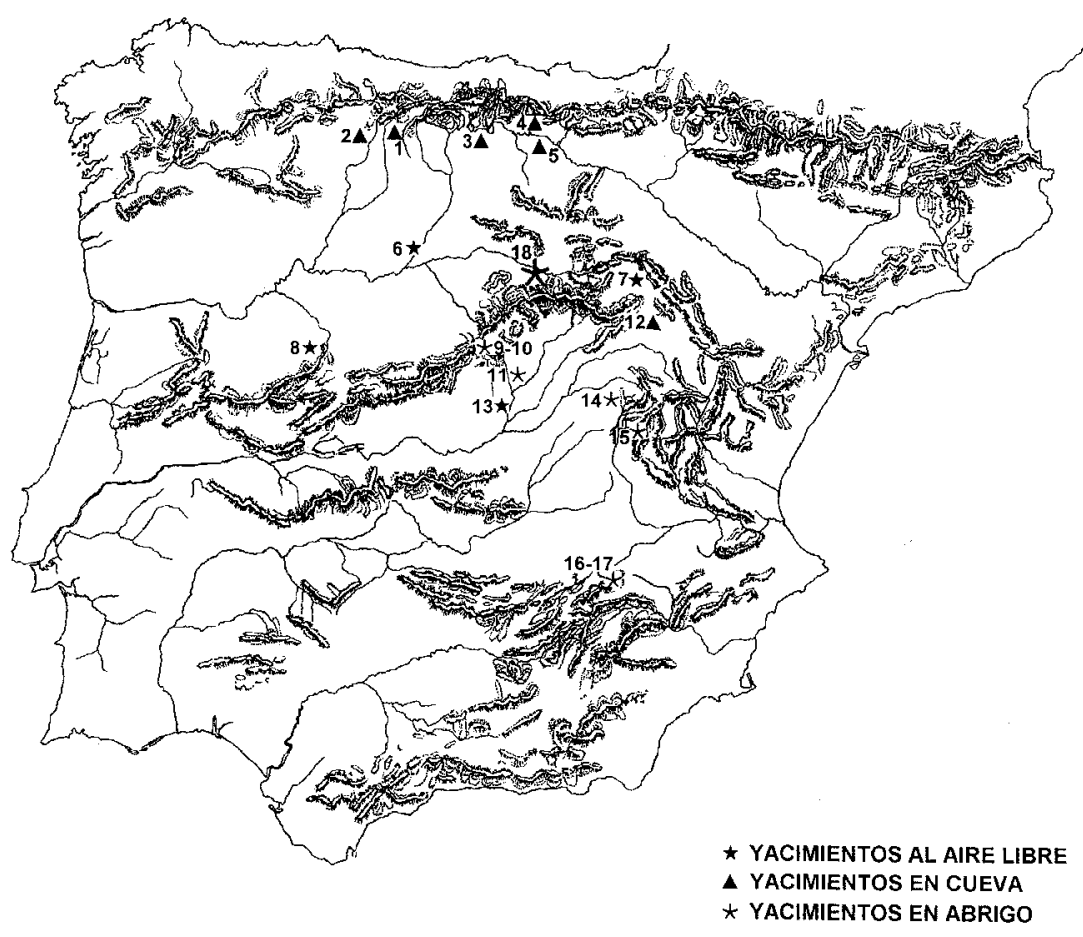

Figura 1. Repartición de los yacimientos citados en el texto, diferenciando la tipología de las estaciones: 1. Cueva de la Uña (Uña, León). 2. Cueva del Espertín (Burón, León). 3. Cueva del Níspero (Orbaneja del Castillo, Burgos). 4. Cueva del Caballón (Oña, Burgos). 5. Cueva de la Blanca (Oña, Burgos). 6. El Palomar (Mucientes, Valladolid). 7. Villalba (Villalba, Soria).

8. La Dehesa (Tejado de Béjar, Salamanca). 9. Jarama I(Valdesotos, Guadalajara).

10. Jarama II (Valdesotos, Guadalajara). 11. Abrigo de la Peña Capón (Muriel, Guadalajara).

12. Cueva de la Hoz (Santa. M. ${ }^{2}$ del Espino, Guadalajara). 13. El Sotillo (Madrid). 14. Buendía (Alcohujate, Cuenca). 15. Verdelpino (Cuenca). 16. Abrigo del Palomar (Ayna, Albacete). 17. Abrigo del Molino Vadico (Yeste, Albacete). 18. Estebanvela (Segovia).

sin embargo, que las propias condiciones del yacimiento - al aire libre y junto a un importante taller de sílex atribuido al Musteriense- así como el escaso conocimiento de los inicios del Paleolítico Superior en la Meseta, dificulta enormemente su interpretación así como su adscripción cronológica.

Dentro también del ámbito de la cuenca del Duero, en la vertiente norte del Sistema Central, se sitúa la Dehesa del Tejado de Béjar (Salamanca). Este asentamiento al aire libre ha proporcionado un único nivel de ocupación con una abundante industria lítica de carácter microlítico, atribuida por su descubridor al Magdaleniense Superior Final. En este caso los útiles sobre hojita son claramente el grupo dominante, seguido del grupo de los buriles, 
Tos cuales también ofrecen un porcentaje alto en relación con los raspadores. Entre los diversos se incluye un numeroso lote de nódulos o prismas de cuarzo cuya cronología resulta problemática, ya que éstos son frecuentes en contextos neolíticos y megalíticos. Asociada a esta industria se incluye una plaqueta en esquisto con incisiones en la que J. Fabián (1986) cree reconocer una posible figura de antropomorfo.

El único sitio conocido hasta el momento en la provincia de Segovia del Paleolítico Superior y el más cercano al conjunto de Domingo García es Estebanvela, aunque como veremos más adelante su cronología en absoluto permite relacionarlo con este complejo artístico. Esta estación se sitúa en el extremo noreste de la provincia de Segovia, lindando con la de Soria y dentro del término municipal de Estebanvela. Se trata de un abrigo colmatado, orientado al suroeste y localizado en la margen derecha del arroyo Guisejo, tributario del río Riaza, dentro de la cuenca del río Duero. Se encuentra en las estribaciones de la sierra de Ayllón, a 1.080 metros sobre el nivel del mar, incluyéndose así en la categoría de yacimientos situados a gran altura. Hay que considerar, además, su situación cercana a los extensos llanos sorianos que le confiere una posición estratégica como lugar de paso natural.

Fue descubierto en 1992 con motivo de la realización de la carta arqueológica de la zona. En 1993 fue visitado en varias ocasiones para valorar su importancia de cara a una futura intervención arqueológica. El relleno está protegido por la visera del abrigo en conglomerado, aunque ésta ha sido parcialmente desmantelada y aparece en forma de grandes bloques junto con otros sedimentos que debieron formar parte del relleno, creando un talud de derrubios delante del yacimiento. El paquete sedimentario que constituye el relleno alcanza una potencia aproximada de 2,40 m., aunque sólo una limpieza exhaustiva del perfil estratigráfico permitiría precisar la potencia real del depósito. Éste está formado por arcillas de tonalidad anaranjada, en las que se intercala el nivel arqueológico de arenas de color grisáceo.

La industria lítica examinada, procedente del talud y carente por tanto de cualquier referencia estratigráfica, está tallada sobre sílex blanco, aunque también está presente el sílex negro, gris y algún ejemplar de sílex jaspeado. En una proporción mucho menor están representados la cuarcita y el cuarzo (figura 2). Desde el punto de vista del soporte parece tratarse de una industria laminar, aunque también es frecuente la presencia de lascas. Las hojitas, por el contrario, aparecen mínimamente representadas, si bien puede deberse al propio carácter de recogida de los vestigios arqueológicos. Dentro del grupo de los materiales retocados destacan mayoritariamente los raspadores, en general cortos, siendo frecuentes los unguiformes. Existen, además, algunas hojas retocadas, varias raederas y una puntita de dorso. 

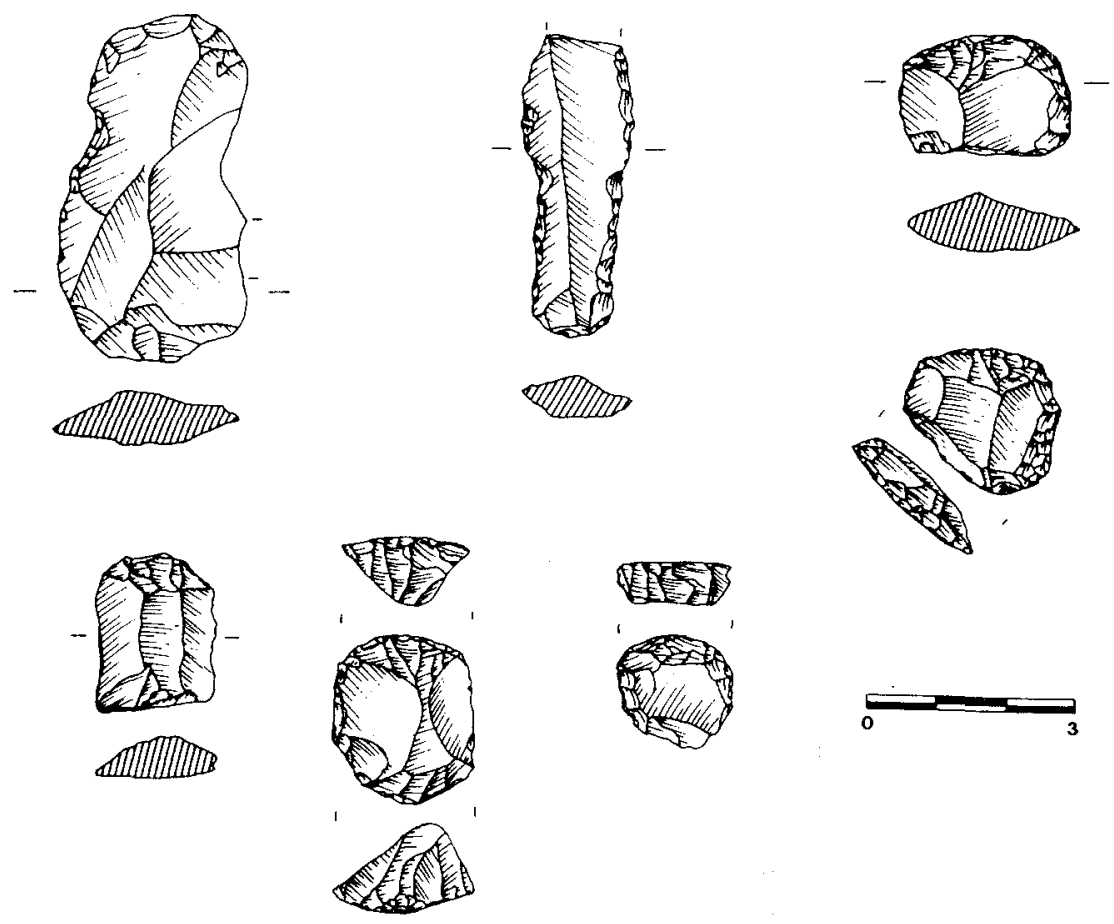

Figura 2. Industria lítica recogida en superficie en el yacimiento de Estebanvela (Segovia). Se trata fundamentalmente de raspadores en extremo de lasca, en extremo de hoja y en abanico.

Por el momento no se ha recuperado ningún elemento de industria ósea, aunque si se conservan numerosos vestigios faunísticos, en general muy concrecionados y bastante alterados. La mayoría son fragmentos indeterminados de huesos largos o esquirlas de diáfisis de herbivoros, además hemos podido identificar dos fragmentos de molares de équido y un fragmento de mandíbula inferior izquierda de lagomorfo.

Entre el conjunto de materiales localizado al pie del abrigo destaca por su enorme interés el hallazgo de dos pequeñas plaquetas y un par de cantos aplanados en esquisto, decorados con finas incisiones grabadas (figura 3 ).

Paralelos de estas obras encontramos en niveles del Aziliense o Magdaleniense Final de los yacimientos franceses de Rochedane (Doubs), Pagès (Lot), Villepin (Dordogne), Rhodes II (Ariège), Dufaure (Landes) y Espèlugues (Hafltes Pyrenées), entre otros (Thevenin, A., 1983; Couraud, 

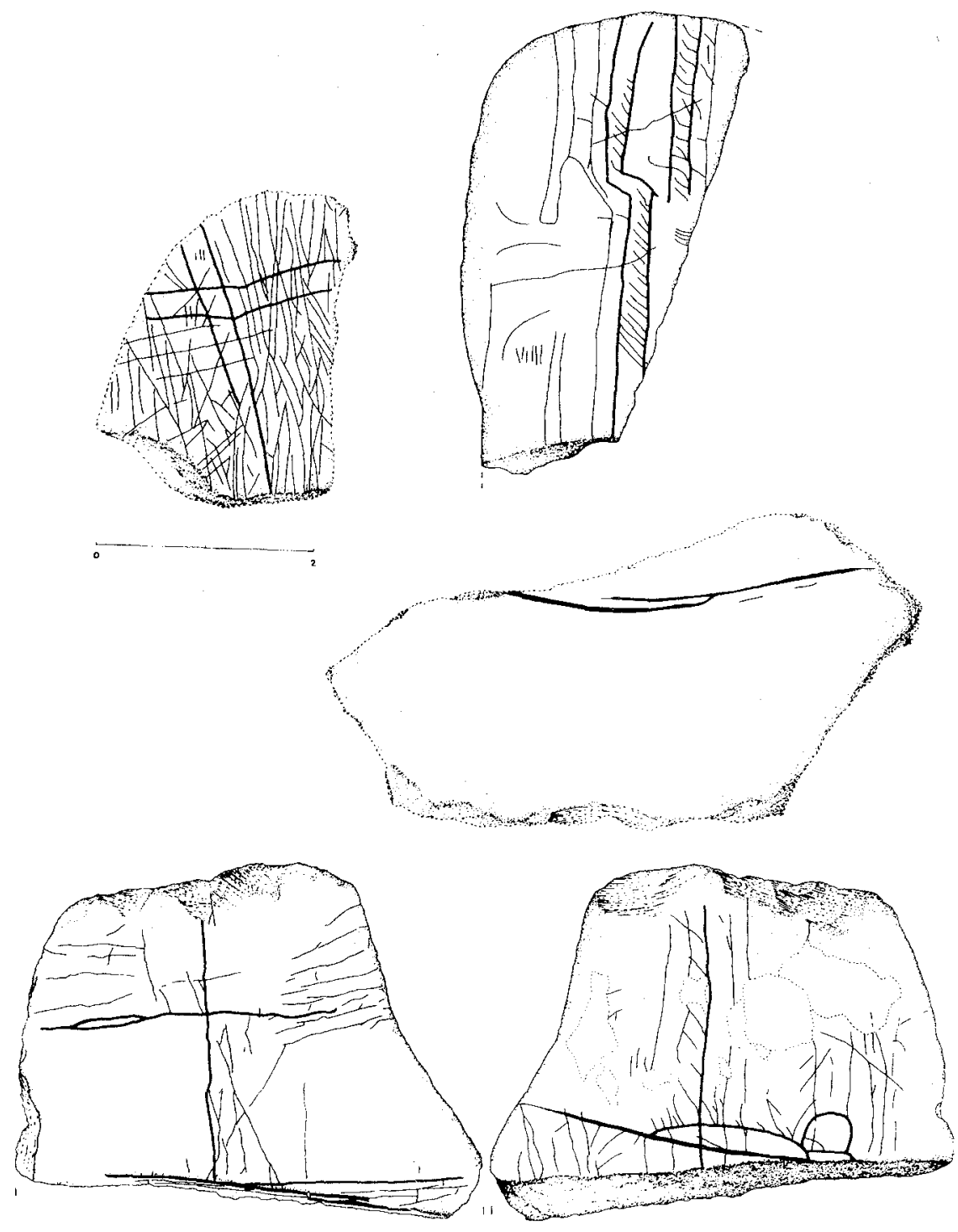

Figura 3. Plaquetas y cantos de exquisto del yacimiento de Estebanvela (Segovia). 
C., 1985; D' Errico, F., 1995). Algunos motivos ligeramente similares al de la pieza $\mathrm{n}^{\circ} 4$ de Estebanvela aparecen en Parpalló, Valencia (Villaverde, V., 1994), aunque donde encontramos mayores analogías es en Italia, en Riparo Tagliente, Grotta delle Veneri de Parabita, Paglicci (Broglio, A., 1996) y en otros niveles del Epigravetiense Final italiano.

En resumen, la mayoría de las obras con las que podemos paralelizar el arte mueble de Estebanvela se inscriben en un Magdaleniense Final o Aziliense, momento en el que creemos podría inscribirse la industria lítica y, en general, la ocupación del yacimiento a partir de los restos recuperados hasta la actualidad. Desconocemos si existen uno o más niveles arqueológicos en el abrigo, aunque la industria y el arte mueble son bastante homogéneos y por ahora nos hablan de un único horizonte de ocupación.

En la Meseta Sur, como consecuencia de la intensificación de los estudios en esta zona, se han producido durante los últimos años nuevos e importantes descubrimientos que afectan sobre todo a la provincia de Guadalajara. Los datos más recientes del estudio de esta zona proceden del abrigo de la Peña Capón (Guadalajara). Está situado en las inmediaciones del pantano de Beleña y fue descubierto en 1970 por un equipo de espeleólogos dirigidos por el profesor J. Martínez Santaolalla. El estudio de esta campaña de excavación fue publicada hace unos años en una breve noticia en la que se menciona una industria lítica compuesta por varias hojas de sauce, algunas hojas de laurel y varias puntas de muesca, de lo que se deduce la existencia de una ocupación solutrense. Asimismo, y a partir también de los materiales exhumados en 1970, se hace referencia a otro conjunto industrial, constituido por rapadores espesos, buriles, cuchillos de dorso y denticulados, a partir del cual se presume la existencia de una fase de cronología más antigua «quizá auriñaciense» (Alcolea, J.J., et alii, 1995).

Recientemente se ha dado a conocer el hallazgo del abrigo de Buendía, un nuevo asentamiento del Paleolítico Superior en la cuenca del Tajo, en proceso de estudio. Este yacimiento, a orillas del pantano del mismo nombre y al sur de la población de Alcócer en Guadalajara, pero dentro ya de los límites de la provincia de Cuenca, se sitúa entre los páramos de la Alcarria y las estribaciones occidentales de la serranía de Cuenca. Precisamente en esta serranía, y a tan sólo unos $50 \mathrm{~km}$., está ubicado Verdelpino con el que, como veremos más adelante, Buendía presenta estrechas analogías.

El estudio preliminar de sus vestigios muestra una industria lítica realizada en sílex gris o blanco, generalmente sobre lascas de gran tamaño, de primer o segundo orden de extracción. Los útiles más frecuentes en este repertorio son los buriles y dentro de ellos destacan los diedros. Muy inferiores numéricamente son los útiles sobre hojita y el grupo de los raspadores. 
Existen, además, algunos útiles compuestos, raederas, perforadores, truncaturas y piezas con retoque continuo.

La industria ósea está ausente de Buendía, por el momento, debido probablemente a la acidez de los sedimentos y al lavado que éstos han sufrido de los carbonatos. Existen, sin embargo, varios restos faunísticos, en algunos casos bastante alterados.

Los datos con los que contamos del abrigo de Buendía son todavía muy provisionales y habrá que esperar a la excavación para una mejor valoración de este nuevo e importante asentamiento de la Meseta Sur. En cualquier caso lo que sí parecen apuntar los primeros análisis es que se trata de un lugar de ocupación magdaleniense, fechado por C14 en el $14.380 \pm$ 90 B.P. (Utc- 4006), probablemente utilizado como lugar de talla primaria y relacionado directamente con el aprovisionamiento y explotación del sílex, muy abundante en sus inmediaciones (Cacho, C., y Pérez, S., 1995).

El yacimiento de Buendía presenta un innegable paralelismo con el cercano abrigo de Verdelpino (Cuenca), en concreto con sus niveles inferiores ( $V$ y VI). Aquí los buriles son también el grupo dominante y «triplican ampliamente el índice de los raspadores". Los útiles sobre hojita son ligeramente superiores en Verdelpino, pero como ocurre en Buendía, se destaca la importancia de las hojitas con retoque marginal frente a las de dorso rebajado (Moure, J.A., y López, P., 1979). Estos niveles de Verdelpino, y sobre todo el $V$ ya que el VI era prácticamente estéril, fueron definidos en su momentos como magdalenienses, sin precisar una etapa concreta, dada la ausencia de paralelos próximos y una secuencia regional del Paleolítico Superior. Sin embargo, si se consideran las dataciones radiocarbónicas (14.000 \pm 520 B.P. nivel V B y $12.930 \pm 470$ B. P., nivel VA) y los análisis polínicos estas ocupaciones, según sus investigadores, se situarían en un Magdaleniense Superior (Moure, J.A., y Fernández, M., 1977).

De todos es bien conocido la presencia de Paleolítico Superior en las terrazas del Manzanares, en particular del Solutrense, evidenciado en el Sotillo, Almendro, arenero Valdivia, Nicasio Poyato (Pérez de Barradas, J., 1919, 1929, 1935) y en arenero Vidal (Pericot, L., y Fullola, J.M., 1981). La recogida de las industrias sin referencia estratigráfica alguna, así como los avatares sufridos por muchas de estas colecciones y la desaparición de los antiguos asentamientos paleolíticos con la expansión urbanística de la ciudad de Madrid, hace totalmente irrecuperable la información que sobre estas ocupaciones hubiéramos podido tener. Sin embargo, merece un lugar destacado el estudio tecno-tipológico, realizado por A. Martínez (1984), sobre la colección del Sotillo que demostró, a pesar de los problemas expuestos, la adscripción de este repertorio lítico al Solutrense. 
Por último, hay que mencionar el Alto valle del Segura donde se han localizado, en las cercanías de la cueva del Niño, algunos abrigos ocupados durante el Paleolítico Superior. Las breves noticias publicadas sobre estos hallazgos y por tanto la escasa documentación existente dificulta enormemente la valoración de estos nuevos sitios. En cualquier caso los autores mencionan tres yacimientos en los que habrían encontrado indicios de $\mathrm{Pa}$ leolítico Superior o Epipaleolítico: Tus, Palomar y Molino del Vadico (Córdoba, B., y Vega, L.G., 1985). El estudio de este último fue objeto de una memoria de licenciatura en la que a partir de sus materiales se adscribe su ocupación al Epipaleolítico microlaminar y al Neolítico (Córdoba, B.,1983; Vega, L.G., 1993). Nosotros, sin embargo, pensamos que algunas de sus industrias más antiguas podrían indicarnos más bien un Magdaleniense Final. El yacimiento de este área que parece revestir mayor interés es el abrigo del Palomar. Éste se localiza en las estribaciones de la Sierra de Alcaraz, y en él se encontraron hace ya unos años, en superficie, un grupo de útiles («una punta de aletas y pedúnculo, raspadores con retoque plano y una hoja con retoque cubriente fracturada, entre otros») fácilmente encuadrables en el Solutrense (Córdoba, B., y Vega, L.G., 1985). El interés de esta noticia es evidente y esperamos que las excavaciones en curso de este yacimiento contribuyan a ampliar el panorama del poblamiento meseteño. Por otra parte, este área, como así ocurre con el núcleo de Buendía y Verdelpino en Cuenca, serán yacimientos claves para el análisis de las relaciones entre el Mediterráneo español y el interior peninsular (Cacho, C., y Pérez, S., 1995).

\section{EL ARTE RUPESTRE}

El arte Paleolítico de los territorios encuadrados en la unidad geomorfológica conocida como Meseta, si bien es conocido a través de algunas de sus manifestaciones desde comienzos de este siglo (Breuil, H., y Obermaier, H., 1913; Hernández, E., 1917), no ha sido objeto de estudios de conjunto hasta hace muy pocos años (Balbín, R. de, et alii, 1992; Balbín, R. de, y Alcolea, J.J., 1994; Gómez, J.A., 1993).

Hasta la divulgación de estas primeras síntesis, los estudios sobre las representaciones rupestres del interior peninsular se habían limitado al registro monográfico de las estaciones con arte conocidas o a la revisión de algunas de ellas. En todos estos trabajos parece dejarse sentir la idea de que cualquier manifestación artística perteneciente al Paleolítico Superior que pueda darse en las tierras de la Meseta debe ser señalada inmediatamente con los adjetivos excepcional y marginal o, en el mejor de los casos, 
como un simple reflejo de los desarrollos artísticos de la zona franco-cantábrica y del Levante español, negando a las representaciones del centro de la Península cualquier viso de personalidad propia y de una posible identidad como fenómeno característico de la región en la que aparecen.

Esta forma de ver el arte Paleolítico meseteño tiene un gran arraigo en los estudios especializados, perdurando de forma tenaz incluso en algunas de las más recientes recopilaciones, en las que aún es posible encontrar referencias al "grupo marginal del interior peninsular" (Gómez, J.A., 1993), como mero trasunto de los desarrollos de las grandes zonas artísticas clásicas de la periferia peninsular.

La falta de información arqueológica que se tiene sobre el Paleolítico Superior de la Meseta es debida, en nuestra opinión, más al escaso auge y a la precariedad de resultados en la investigación sobre esta fase de la Prehistoria en nuestra región que a una realidad objetiva. La abundancia de yacimientos con arte correspondiente a este momento no puede relacionarse, de ningún modo, con un vacío de referencias arqueológicas pero el hecho cierto es que, todavía hoy, es muy difícil establecer sobre elementos materiales y, sobre todo, estratigráficos, el contexto cronológico y cultural en el que se produciría el desarrollo de los procesos artísticos superopaleolíticos del interior peninsular.

Este notable desconocimiento de la secuencia arqueológica parece haber influido en los estudios sobre las representaciones artísticas de ese momento, condicionando la forma de entender una serie de manifestaciones que, si tenemos en cuenta los últimos descubrimientos, como son los conjuntos de Domingo García que ahora estudiamos, de Siega Verde (Salamanca) y de Foz Côa (Portugal), muestran de una forma cada vez más contundente la existencia de una nueva "provincia" - si se nos permite tal denominación- dentro del mundo del arte rupestre paleolítico, cuyas características, incuestionablemente vinculadas en aspectos técnicos y estilísticos a las series cantábricas y levantinas, denotan sin embargo una gran originalidad que comienza en el hecho de su localización al aire libre.

Esta circunstancia ha provocado una inmediata inversión de los conceptos utilizados hasta ahora en la descripción de las características generales de la zona. Las representaciones al aire libre, conocidas hasta hace pocos años como excepciones y casos aislados que aparecían dentro de un complejo de cuevas que contenían la práctica totalidad de los conjuntos artísticos conocidos, han pasado a constituir el núcleo principal del arte documentado en la Meseta, superando ampliamente en número de figuras, con tan sólo cuatro yacimientos, a todas las estaciones artísticas conocidas hasta ahora en la zona. 
Se elimina, además, el concepto de figura aislada que el primer descubrimiento de Domingo García (gran caballo de la Roca 12), junto con las figuras de Mazouco (Portugal) (Jorge, S.O., et alii, 1982) y de Piedras Blancas (Almería) (Martínez, J., 1986-1987; 1992) habían conseguido, de algún modo, fijar como norma de este tipo de arte.

Por otra parte, no puede perderse de vista la originalidad de algunas de las técnicas empleadas, como son el piqueteado -comparado en ocasiones con el tamponado utilizado en algunos motivos pictóricos en cueva (Balbín, R. de, y Moure, J.A., 1988) o la abrasión.

La novedad de estos descubrimientos en los aspectos referidos hace que su análisis sea realmente complejo mediante el empleo de los grandes sistemas de estudio del arte paleolítico, donde a duras penas encuentran cabida, si no es en la comparación de cuestiones meramente morfométricas y de apariencia de las representaciones, y a cuya revisión fuerzan necesariamente, como ya se ha indicado en otras ocasiones (Ripoll López, S., et alii, 1994).

Se intentará resumir, a continuación, el estado actual de la investigación del arte paleolítico meseteño, siguiendo para ello las pautas establecidas en las agrupaciones contempladas por J.A. Gómez (1993).

Se distingue, desde el punto de vista geográfico, la existencia de cuatro grupos zonales (figura 4):

- Alto Valle del Ebro, que incluye las cuevas de Penches, Atapuerca, Ojo Guareña y Caballón (Burgos).

- Sistema Central, en el que se documentan los conjuntos de Domingo García y de la cueva de La Griega, junto con la placa de pizarra grabada localizada en Villalba (Soria).

- Cuenca del Tajo, con las cuevas de Los Casares, La Hoz, El Turismo, El Reno y Jarama II (Guadalajara), El Reguerillo (Madrid), El Niño (Albacete), Maltravieso, La Mina de Ibor (Cáceres) y Escoural (Portugal).

- Zona occidental de la Cuenca del Duero, en la que se localizan las estaciones al aire libre de Mazouco y Foz Côa (Portugal) y Siega Verde (Salamanca).

Dentro del conjunto de yacimientos reseñado, adquiere un protagonismo destacado la técnica del grabado, tanto en cueva como al aire libre, habiendo desplazado estos últimos conjuntos a los conocidos de antiguo en cuevas profundas, tanto en número como en diversidad en cuanto al tipo de representaciones. Volveremos más adelante a ellos, tras sintetizar la información conocida sobre manifestaciones pictóricas y arte mueble. 


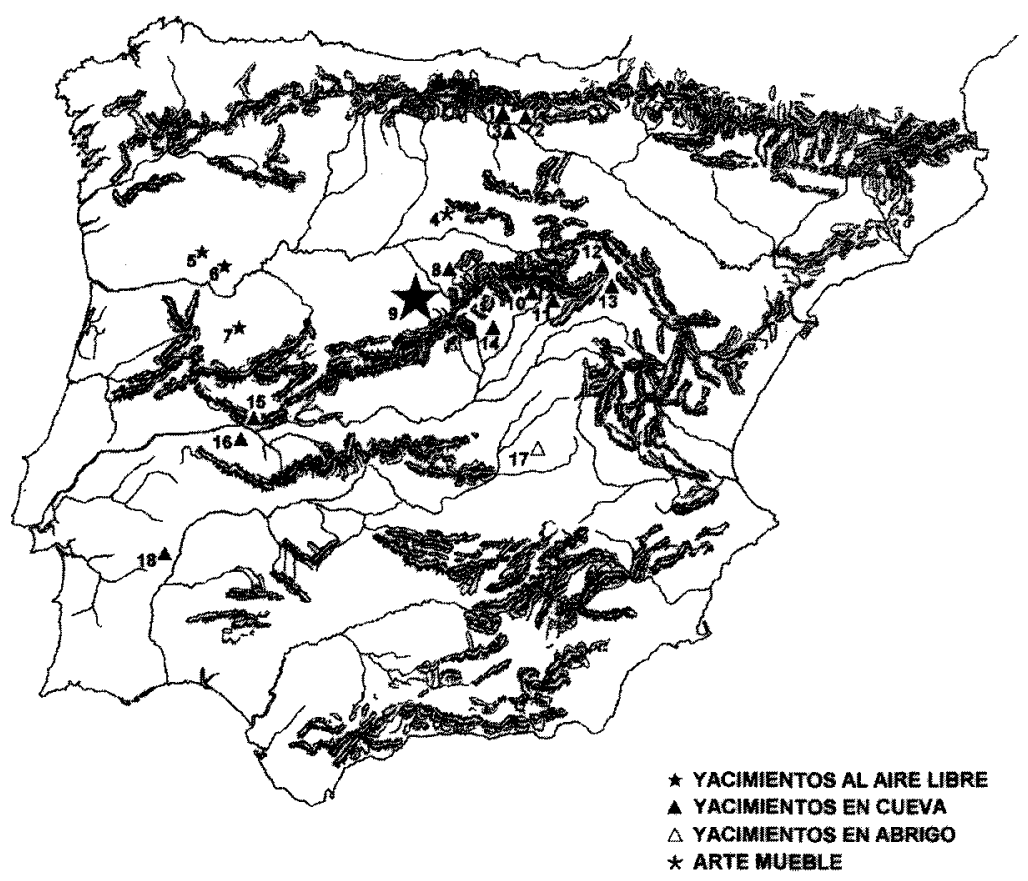

Figura 4. Dispersión geográfica de los yacimientos citados en el texto, diferenciando la tipología de la estación: 1. Penches (Barcina de los Montes, Burgos). 2. Atapuerca (Iboas, Burgos). 3. Ojo Guareña (Sotocuevas, Burgos). 4. Villalba (Villalba, Soria). 5. Foz Côa (Vila Nova de Foz Côa, Portugal). 6. Mazouco (Freixo de Espada-à-Cinta, Portugal). 7. Siega Verde (Villar de Argañán, Salamanca). 8. La Griega (Pedraza, Segovia). 9. Conjunto de Domingo García (Segovia). 10. El Turismo (Tamajón, Guadalajara). 11. El Reno (Tamajón, Guadalajara). 12. La Hoz (Santa M.ㄹ del Espino, Guadalajara). 13. Los Casares (Riba de Saelices, Guadalajara). 14. El Reguerillo (Patones, Madrid). 15. La Mina de Ibor (Castañar de Ibor, Cáceres). 16. Maltravieso (Cáceres, Cáceres). 17. El Niño (Ayna, Albacete). 18. Escoural (Santiago do Escoural, Evora, Portugal).

\section{ARTE MUEBLE}

Los hallazgos de arte mueble en la zona objeto de estudio se reducen a tres referencias, dos en la Submeseta Norte y uno en la Cuenca del Tajo.

Entre los materiales aparentemente magdalenienses de la cueva del Caballón (Burgos) (García-Soto, E., 1983) se menciona la existencia de lo que García Soto describe como un bastón de mando perforado, grabado 
con una cabeza de herbívoro, a partir de un dibujo de Cabré y algunas fotografías antiguas. En la actualidad se desconoce en qué colección se encuentra.

El hallazgo fuera de contexto, en los años ochenta, de una placa de pizarra decorada en el Barranco Hondo, en el término de Villalba (Soria), está dotado de un especial significado, no ya sólo por el enriquecimiento que supone para el horizonte artístico de la Meseta, sino además porque esta obra de arte mueble implica la existencia - aunque en la actualidad haya desaparecido- de un nuevo lugar de ocupación en la región. Esta placa, grabada por las dos caras, presenta a pesar de su tamaño, un buen número de figuras animales, trece en cada cara distribuidos entre équidos y caprinos, y se sitúa cronológicamente en un Solutrense Final - Magdaleniense Inicial, dentro de los límites del Estilo III de A. Leroi-Gourhan (Jimeno, A., et alii, 1991). Otros autores, sin embargo, prefieren encuadrarla en un Magdaleniense Final, debido a la existencia más o menos clara de ocupaciones de este período en áreas próximas a este yacimiento (Utrilla, P., y Mazo, C., 1996). Éste parece ser el caso del yacimiento de la Peña del Diablo, en la provincia de Zaragoza, aunque muy cerca ya de la de Soria. (Utrilla, P., 1995).

En 1988, se publicó una interesante pieza mobiliar de bulto redondo que representa la figura de un mustélido (posible glotón). Esta pieza fue encontrada descontextualizada en el yacimiento de Jarama II, una pequeña cueva situada en el alto valle del Jarama, en la vertiente sur del Sistema Central. Más tarde, este yacimiento fue excavado proporcionando un conjunto de materiales que, aunque escasos, han podido atribuirse al Magdaleniense Inferior a partir del análisis de la industria ósea (Adán, G., y Jordá, J.F., 1989; Jordá, J.F., et alii, 1989). Próximo a éste se localiza Jarama I, atribuido en un principio a las etapas finales del Paleolítico Superior, pero la ausencia de contexto estratigráfico junto con un escaso número de piezas en las que no existen elemento diagnósticos, nos hace compartir la opinión de sus investigadores que consideran «un tanto aventurado determinar la adscripción cultural del conjunto" (Estrada, R., et alii, 1992).

\section{PINTURA RUPESTRE}

Se documentan sólo cuatro puntos en los que se localizan motivos pictóricos. Dos de ellos se encuentran en la provincia de Burgos (Cueva Mayor de Atapuerca y Cueva Palomera) (Gómez, J.A., 1993), otro en la de Cáceres (Cueva de Maltravieso) (Ripoll López, S., et alii, 1997) y un cuarto en Albacete (Cueva de El Niño) (Almagro, M., 1971, 1972). No se 
incluyen en este apartado las representaciones de la cueva de Los Casares (Guadalajara), minimizadas por el conjunto de grabados localizados en dicha estación.

La Cueva Mayor de Atapuerca (Burgos) es una de las tres galerías del complejo kárstico de Atapuerca. En 1910, M. Alcalde del Río comunicó al abate $\mathrm{H}$. Breuil el hallazgo en ella de pinturas rupestres de adscripción paleolítica (Gómez, J.A., 1993).

H. Breuil localizó una cabeza pintada en rojo (1932), recientemente mencionada por A. Moure (1985), con algunos problemas en cuanto a su identificación zoológica, puesto que ha sido identificada unas veces como perteneciente a un caballo y otras como a un oso. El abate menciona también la existencia de signos en rojo de estilo paleolítico Cantábrico (Breuil, H., 1932).

En la Sala de las Pinturas o de los Triángulos de Cueva Palomera (Burgos) se descubrieron en 1968 una serie de representaciones pintadas o perfiladas en negro, entre las que se identificaron ciervos, cabras, caballos y bóvidos, junto con un jabalí y un elefante o mamut. En ellas, atribuidas al Magdaleniense aunque con bastantes dudas (Jordá, F., 1968-69; Moure, J.A., 1985), se observan figuras naturalistas, en las que se señala el empleo de la perspectiva torcida y la aparición de líneas de despiece, con una marcada tradición paleolítica. Junto a estos motivos, se localiza una serie de manifestaciones esquemáticas con características postpaleolíticas que sugieren una reutilización del panel en la Edad del Bronce, como es posible comprobar también en otros yacimientos de la Meseta (sirvan como ejemplo los paneles de la cueva de La Griega, en Segovia), auténticos palimsestos en los que encuentran cabida motivos artísticos paleolíticos y postpaleolíticos, junto con un amplio muestrario epigráfico de épocas romana y posteriores.

En tierras extremeñas, la cueva de Maltravieso (Cáceres) acaba de ser objeto de un nuevo estuóio (Ripoll López, S., et alii, 1997), aumentándose considerablemente la cantidad de sus motivos, habiendo visto prácticamente triplicado su número las improntas de manos, siempre en negativo. Junto a ellas, signos, figuraciones zoomorfas y trianguliformes grabados completan el repertorio artístico de este yacimiento, cuya cronología, a falta de contexto arqueológico, se situó, en un principio, dentro del ciclo auriñaco-perigordiense (Breuil, H.; 1952; Almagro, M., 1960 y 1969). Posteriormente, a partir de criterios artísticos y asociativos, este conjunto fue clasificado en el Magdaleniense Medio (Jordá, F., 1968; Jordá, F. y Sanchidrían, J.L., 1992). Aunque las últimas investigaciones llevadas a cabo en la cavidad consideran como más probable una cronología antigua basada en la 
existencia de manos datadas en algunas cuevas francesas (Ripoll López, S., et alii, 1997).

La cueva del Niño (Albacete) era conocida como tal desde antiguo, pero sus pinturas fueron descubiertas por casualidad para la ciencia en 1971. Seguidamente M. Almagro se ocupó de su estudio y documentación (1971, 1972), inventariando un total de 17 figuras de animales entre las que identificaba ciervos, ciervas, caballos, cabras y un bóvido, también se documentaron varios signos - claviformes, serpentiformes, líneas y puntos-. En 1992, R. de Balbín realizó una revisión de la cavidad completando uno de sus paneles en el que incluyó dos nuevas figuras ( 1 caballo y 1 claviforme). Todas estas representaciones fueron pintadas mayoritariamente en color rojo y algunas en negro. Desde los primeros análisis de M. Almagro se destaca la presencia de una composición figurativa del panel principal, en el que los ciervos aparecen como el tema central.

En cuanto a la edad de las manifestaciones M. Almagro Gorbea observó la existencia de una cronología relativa por medio de las superposiciones. Ante la ausencia de yacimiento arqueológico incluyó estas manifestaciones dentro del Estilo III de A. Leroi-Gourhan. Posteriormente J. Fortea (1978) estableció dos grupos diferentes que se encuadraban entre el Estilo III y IV respectivamente. El último estudio realizado por R. de Balbín y J.J. Alcolea (1994) no añade aportaciones significativas y coincide en asignar una cronología Solutrense Final/Magdaleniense Inicial al yacimiento, tal y como aplica a otras tantas estaciones de la Meseta.

\section{GRABADOS EN CUEVA}

Este tipo de representaciones están presentes en la Cuenca del Duero en los conjuntos de las cuevas de Penches (Burgos) y de La Griega (Segovia).

Es abundante la documentación existente sobre la cueva de Penches (Burgos), desde que sus grabados fueran dados a conocer por el Padre M. Gutiérrez (1917). E. Hernández la estudió ese mismo año y, con posterioridad, ha sido objeto de revisiones por parte de Martínez Santaolalla (1926), E. Ripoll (1957), F. Jordá (1964), E. García-Soto (1983) y J.A. Moure (1985).

A partir de la primera descripción de cinco caprinos grabados - uno de ellos, además, pintado y desaparecido actualmente- se han sumado nuevos motivos al conjunto. E. García-Soto (1983), describió motivos esquemáticos y algunos a los que otorga un carácter antropomorfo. La atribución paleolítica de estos grabados ha sido contestada, no obstante, por 
otros autores, que se inclinan por una cronología postpaleolítica (Moure, J.A., 1985; Balbín, R. de, y Alcolea, J.J., 1994), aunque parece existir un claro sustrato superopaleolítico.

La última revisión conocida se debe a A.I. Ortega (1990), quien aumenta el número de motivos zoomorfos con dos nuevos caprinos, un équido y un bóvido. No existen conclusiones sólidas sobre la cronología de estas representaciones, si bien las figuras de caprinos podrían ser encuadradas sin grandes dificultades dentro del Estilo IV antiguo de A. Leroi-Gourhan a partir de los convencionalismos observados en ellas (apariencia estática, despieces sencillos indicadores de volumen, etc.). De todos modos, como reconoce Balbín, no sería posible «oponer una resistencia muy sólida» a su inclusión en el Estilo lil (Balbín, R. de, y Alcolea, J.J., 1994).

El segundo yacimiento citado, la cueva de La Griega (Segovia), es una de las cavidades más conocidas de la Cuenca del Duero. La localización del importante conjunto de grabados paleolíticos que contiene no comenzó, sin embargo, hasta 1970, publicándose al año siguiente la primera cabeza incisa de caballo identificada en esta cueva (Almagro Gorbea, M., 1971).

Sus galerías fueron estudiadas entre 1980 y 1982 por el investigador francés $G$. Sauvet, quien localizó veinticinco nuevas figuras de équidos y cérvidos, que dieron lugar al desarrollo de nuevas teorías, argumentándose la conexión con la zona mediterránea a partir, por ejemplo, de los convencionalismos en las representaciones de los équidos — crineras en escaión, morros inacabados, etc.- estudiados por J. Fortea en las plaquetas de El Parpalló (Fortea, J., 1978).

No era posible tampoco obviar ciertos paralelismos con las representaciones de cavidades norteñas, situación que desembocó en el estudio del papel de este yacimiento, y de las tierras de la Meseta, como eslabón de relación o zona de paso entre los repertorios artísticos cantábricos y los del Levante (Sauvet, G. y S., 1983; Sauvet, G., 1985, 1986).

La cronología propuesta en este primer estudio de La Griega atribuye las representaciones animales de este yacimiento a una fase cultural solutrense, estilísticamente encuadrable entre el Estilo II pleno y el III inicial del sistema de A. Leroi-Gourhan. En este sentido se ha manifestado la mayoría de los restantes autores que se han ocupado de este yacimiento (Almagro, M., 1971; Balbín, R. de, et alii, 1992; Balbín, R. de y Alcolea, J.J., 1994), lo que situaría los grabados de esta cueva en una fase antigua de los desarrollos artísticos del Paleolítico en la Meseta.

En el momento de escribir estas líneas acaba de aparecer el último estudio global del arte de esta cavidad, realizado entre 1985 y 1991 por un 
equipo dirigido por $\mathrm{M}^{a}$.S. Corchón. Su labor ha permitido multiplicar tanto el número de representaciones conocidas, prácticamente cuadruplicado, como el bestiario identificado en el conjunto. Habrá que esperar a su publicación para conocer con detalle tanto la composición del conjunto y la distribución espacial de sus figuras, como la última propuesta de cronología para el mismo, expuesta hace pocos años por la responsable de este trabajo de investigación, relacionando esta cavidad con un contexto solutrense retardatario, enmarcado en la fase fría Dryas I (Corchón, Ma.. ., et alii, 1991).

En la submeseta Sur son siete los conjuntos de grabados paleolíticos en cueva conocidos hasta el momento, y que están siendo objeto de nuevos estudios y revisiones en los últimos años.

La cueva de El Reguerillo (Madrid) se encuentra en fase de revisión por parte de un grupo de investigadores de la Universidad Autónoma de Madrid. Se conocen de ella noticias antiguas que hacen referencia a un posible antropomorfo (Breuil, H., 1920) y a un pisciforme, así como a tres caprinos y un probable mamut (Loriana, Marqués de, 1942; Maura, M., 1952) que aún no han sido comprobadas.

La cueva de La Hoz (Guadalajara) fue descubierta por J. Cabré, que la dio a conocer en 1934, junto con la de Los Casares (1934). Más tarde, A. Beltrán e I. Barandiarán describieron grabados de équidos y algunos signos en sus galerías (Beltrán, A. y Barandiarán, I., 1968).

Un nuevo estudio de esta cavidad (Balbín, R. de, et alii, 1992) dio como resultado un espectacular aumento en el número de figuras, repartidas por toda la cueva, modificándose igualmente el repertorio faunístico, en el que se incluyen bóvidos -entre los que se distinguen bisontes y toros (Balbín, R. de, y Alcolea, J.J., 1994)-, cérvidos y caprinos, más una única representación de reno. En lo que se refiere a aspectos técnicos, se da entrada en el repertorio a representaciones pictóricas de animales silueteadas en negro. Distinguen estos investigadores dos grupos de representaciones, a partir de cuestiones técnicas y estilísticas, encuadrando el primero de ellos en el Estilo III, con grandes figuras de grabado profundo y cierto grado de arcaísmo, resueltas sin grandes detalles y con aparición de la perspectiva torcida, crineras en escalón, etc. Un segundo grupo, con figuras de menor tamaño en las que es patente un mayor desarrollo de los detalles - crineras de trazos paralelos, despieces ventrales longitudinales, empleo de la perspectiva absoluta, etc.- es situado dentro del Estilo IV antiguo.

Se incorpora también, como novedad, la existencia de un número significativo de placas de pizarra grabadas con figuraciones animales (Balbín, R. de, et alii, 1992; Balbín, R. de, y Alcolea, J.J., 1994). 
La cueva de Los Casares (Guadalajara), cercana a la anterior, es comparable también con ella en cuanto al tipo de representaciones que contiene. Es conocida desde antiguo (Puig, G., 1896), descubriéndose sin embargo sus representaciones rupestres en el año 1933.

Descrita en un primer momento por J. Cabré (1934), ha sido objeto de diversos estudios, tanto de sus representaciones como de su contenido arqueológico. También como la anterior, está siendo objeto en la actualidad de una nueva revisión por parte de R. de Balbín.

Técnicamente, se observa el predominio del grabado sobre la pintura -roja y negra-, que está escasamente representada. En cuanto al tipo de fauna representada, équidos, bóvidos, cérvidos y caprinos dominan sobre otras especies, que se identifican con rinocerontes - un solo ejemplar-, carnívoros y felinos. Destaca un extenso elenco, poco corriente, de antropomorfos, generalmente representados de perfil y asexuados, que superan en cuanto a porcentaje a algunas de las figuraciones animales (Balbín, R. de, et alii, 1992). Para su encuadre cronológico se emplean una vez más criterios estilísticos, buscándose la similitud de los équidos de tipo arcaico con las de las series cantábricas y levantinas incluidas en el Estilo Ill de A. Leroi-Gourhan y se considera una cronología corta a partir de la aparente homogeneidad estilística de las representaciones. El desarrollo del conjunto se situaría, de esta manera, entre el Estilo III y el IV antiguo de A. Leroi-Gourhan (Balbín, R. de, et alii, 1992).

Recientemente, a raíz de la realización de la Carta Arqueológica de la provincia de Guadalajara fue descubierta una nueva cavidad con arte rupestre. Se trata de la cueva de El Turismo, de la que únicamente se ha dado a conocer un estudio preliminar (Balbín, R. de, et alii, 1995), en el cual se especifica la existencia de 5 conjuntos o paneles en los que se identifican 2 équidos, 3 ciervos, 1 bóvido y varios cuadrúpedos junto con algunos signos — triángulos y zig zag-. Todas estas manifestaciones han sido realizadas mediante la técnica del grabado inciso. Tanto los temas como el volumen total de las figuras nos es desconocido, sin embargo, el estilo general de las representaciones y su proximidad geográfica con las cavidades de la Hoz y los Casares permiten situar cronoestilísticamente a este conjunto entre el Estilo III avanzado y IV antiguo de Leroi-Gourhan.

En el momento de redactar estas líneas nos llega la publicación de una nueva cavidad, la cueva de El Reno (Guadalajara) (Alcolea, J.J., et alii, 1997) situada en el alto curso del río Jarama, en una zona con numerosos yacimientos encuadrables en el Paleolítico Superior. El estudio preliminar muestra la existencia de un total de 20 figuras más o menos claras, entre 
las que se han identificado 13 équidos de los cuales 5 están pintados en rojo, un posible bóvido y otro herbívoro no identificable de rara factura, un bisonte y un caprino pintados en ocre rojo y tres cérvidos, entre los cuales se ha descrito la figura de un reno. Los investigadores de la Universidad de Alcalá de Henares consideran que todas las características morfológicas se corresponden con un verdadero Estilo III de A. Leroi-Gourhan, probablemente hacia el 18.000 B.P., es decir en el inicio del último estadio würmiense. El predominio de las representaciones incisas frente a las pintadas nos lleva a encuadrar esta cavidad, con todas las reservas de su novedad, en este apartado de los grabados en cueva.

En el año 1995 se localizó La Cueva de La Mina de Ibor (Cáceres) (Ripoll López, S., y Collado, H., 1996), que es una pequeña cavidad de poco más de treinta metros de desarrollo. La boca se orienta hacia el Oeste a unos 15 metros sobre el curso actual del río lbor, oculta tras un gran bloque que actúa a modo de terraza.

En esta estación cacereña se han localizado un total de 7 figuras animalísticas entre las que se identifican dos cérvidos, tres équidos, un cuadrúpedo indeterminado y otro cuadrúpedo que hemos descrito como un posible oso. Todas las figuras han sido realizadas por medio de un grabado lineal de sección en «U» 0 « $V »$, muy fino encontrándose el surco de la misma totalmente pulido y recubierto por una fina colada calcítica, lo que corifirma junto con sus características estilísticas, su antigüedad.

El repertorio figurativo de la Cueva de la Mina de Ibor, sigue la corriente iconográfica de las estaciones con manifestaciones de arte paleolítico de la zona extracantábrica. La fauna representada, fundamentalmente caballos y ciervos, incluye sin embargo un animal que aparece escasamente representado en el arte cuaternario como es el oso en proporción con otros animales. Los caracteres estilísticos nos permiten encuadrar este conjunto en un momento final del Paleolítico Superior, posiblemente en un Solutrense Final o un Magdaleniense Inicial.

Si antes nos hemos referido a las cuevas de Maltravieso y de La Mina de lbor, en el límite geográfico de la zona meseteña, en este grupo también tenemos que incluir la cueva de Escoural (Portugal), con un amplio repertorio figurativo, fundamentalmente inciso, aunque asimismo hay algunas representaciones pintadas. La cueva fue descubierta en 1963, apareciendo las primeras noticias de la misma en 1966 (Glory, A., et alii, 1966). Recientemente se ha reestudiado y revisado profundamente en el marco de un proyecto de investigación luso-belga (Lejeune, M., 1996 y 1997), aportando nuevos datos. Este análisis ha contabilizado un total de 
77 representaciones entre las que destacan 17 caballos, 7 bóvidos y gran cantidad de retículas grabadas de edad incierta.

La cronología relativa fundamentada en el estudio de las superposiciones, así como sus paralelismos con otras estaciones peninsulares, lleva a la investigadora belga a encuadrar los temas figurativos en un horizonte cultural solutrense, mientras que el resto de temas esquemáticos les atribuye una cronología muy imprecisa.

\section{GRABADOS AL AIRE LIBRE}

Al referirnos a las manifestaciones artísticas paleolíticas al aire libre, parece obligado iniciar la exposición con las ya usuales referencias a la novedad que dichas representaciones suponen dentro del panorama del arte rupestre de ese momento, así como a su carácter excepcional en el conjunto peninsular.

Sin embargo, ambas definiciones parecen haber quedado ya, en cierto modo, desfasadas, puesto que en el momento actual no deberían constituir, en modo alguno, una novedad - los primeros grabados de Siega Verde fueron descubiertos en 1989, y en 1992 los de Domingo García - ni, mucho menos, una excepción dentro del arte paleolítico peninsular puesto que, si sumamos a los dos conjuntos citados los descubrimientos de Foz Côa y los ya conocidos de años atrás de Mazouco (Portugal) y, fuera de los límites de la Meseta, la figura de Piedras Blancas (Almería) y el conjunto de Fornols Haut (Francia), lo que encontramos es una amplia serie de representaciones con una concreción que, por el momento, parece adquirir un carácter especial en las tierras de la Meseta.

La situación actual parece conformar una región artística de acusada personalidad donde este tipo de yacimientos ha cobrado una inusitada importancia y cuyas características obligan a desterrar viejos $-\mathrm{y}$ modernos- tópicos sobre "zonas marginales", "reflejos de otras áreas», "zona de paso", etc., que hasta ahora mismo han ocupado muchas de las páginas escritas sobre el arte paleolítico de la Meseta dentro del panorama global de las manifestaciones artísticas de ese momento.

El conjunto de arte rupestre al aire libre de Domingo García (Segovia) se encuentra situado en el borde meridional de la Meseta Norte reúne en ocho núcleos más de un centenar de figuras grabadas paleolíticas. El área prospectada se encuentra emplazada en el borde meridional de la cuenca del Duero y al NO de la sierra de Guadarrama, centrándose en la zona 
septentrional hasta rebasar el macizo de Santa María la Real de Nieva en la Meseta Norte.

Las primeras referencias escritas acerca de las manifestaciones artísticas de la comarca de Santa María la Real de Nieva (Segovia) son de principios de siglo (Tuñón, P., 1929), si bien, los trabajos sistemáticos no se iniciarían hasta la década de los setenta con el descubrimiento del caballo piqueteado de «estilo paleolítico» junto a representaciones postpaleolíticas del Cerro de San Isidro en Domingo García (Gozalo, F., 1970). Como consecuencia de esta noticia la profesora Lucas Pellicer comienza su documentación y posterior publicación (1974), siendo a partir de 1981 cuando la investigación pasa a centrarse en el arte paleolítico (Martín, E., y Moure, J. A., 1981).

Nuestra intervención comienza en 1992 a raíz de una denuncia por la voladura de un panel con grabados rupestres postpaleolíticos en la zona de las Canteras. Las acciones emprendidas a partir de este hecho, con el fin de determinar la localización exacta del total de las rocas con incisiones dieron lugar al hallazgo de un importante conjunto de grabados inéditos, de cronología paleolítica, que aquí presentamos. Los trabajos se realizaron en todo momento bajo los auspicios de la Junta de Castilla y León, con un permiso concedido por la Dirección General de Patrimonio y Promoción Cultural para la catalogación de arte rupestre en esta comarca, debido al riesgo que suponía la proximidad de tres canteras de pizarra para las nuevas zonas con grabados.

Desde ese momento comienzan por el actual equipo los trabajos de documentación y prospección en el área de estudio, identificándose hasta la fecha un total de ocho núcleos en una superficie de aproximadamente $40 \mathrm{~km}^{2}$ que superan el centenar de figuras grabadas (Ripoll, S., et alii, 1994b; Ripoll López, S., y L.E.P., e.p.).

Se distinguen dos tipos de técnicas en la realización de las figuras: piqueteado y trazo fino, habiéndose realizado todas sobre una superficie pulida - de color gris- de los esquistos, sin que se aprecien grabados de trazo fino sobre las superficies que se crean a posteriori.

El conjunto está compuesto por representaciones animales, de estilo naturalista que, en todos los casos, se localizan al aire libre y en las superficies lisas de los afloramientos de esquistos del macizo de Santa María la Real de Nieva.

El mapa de distribución de los conjuntos con incisiones de cronología paleolítica, conocidos actualmente indica la existencia de ocho grupos bien diferenciados y separados por espacios aparentemente "vacíos». Estos 
grupos van de Sur a Norte: Santa María la Real de Nieva, Ortigosa del Pestaño, El Cerro de San Isidro, Canteras, Migueláñez, Valdebernardo, Río Eresma y Dehesa de Carbonero.

Entre las especies representadas en el conjunto de Domingo Garcia y dentro del número total de figuras identificadas (115) destaca el elevado porcentaje de équidos $(37,39 \%)$, tendencia generalizada en casi todas las zonas geográficas diferenciadas dentro del conjunto. El segundo grupo es el de los indeterminados $(25,21 \%)$ significativo del alto número de figuras que aparecen incompletas o dañadas por acciones naturales y/o antrópicas. Cérvidos y caprinos mantienen unos índices muy similares, en torno al $15 \%$, siendo los bóvidos la especie menos representada con tan sólo el $7,82 \%$ del total.

En cuanto a su distribución geográfica, cabe destacar que el Cerro de San Isidro, que por otra parte es el de mayor extensión, acumula prácticamente la mitad de los grabados, seguido de las Canteras y en menor medida la Dehesa de Carbonero y demás grupos.

Con todo, pueden observarse una serie de peculiaridades:

a) La abundancia de caprinos en una determinada zona, Canteras, permite sugerir la posibilidad de una relación núcleo-especie, máxime cuando ese número representa la práctica totalidad de los caprinos existentes en todo el conjunto.

b) Una relación similar puede aplicarse al caso de la Dehesa de Carbonero y los équidos. En este caso su representatividad no es debida a la existencia de un mayor número de équidos, sino a su porcentaje dentro del núcleo. Es significativo que en esta zona no se documente ninguna representación de caprinos.

c) En el caso de los bóvidos puede verse de nuevo esta relación núcleo-especie, donde de manera similar al caso de los caprinos, la totalidad, a excepción de dos figuras, se localiza en el Cerro de San Isidro.

d) Los cérvidos, por contra, se distribuyen de una manera uniforme en el conjunto. Aparecen repartidos por igual en el Cerro de San Isidro y en Canteras, estando prácticamente ausentes en el resto de los focos. Algo muy similar ocurre con la distribución de los «indeterminados».

En cualquier caso, y a falta de un estudio más detallado de las relaciones especie-núcleo, se podría plantear como hipótesis de trabajo el que estas relaciones animai-paisaje fuesen reflejo de una mayor variedad del medio en las áreas circundantes, a finales del Pleistoceno. Hecho que parece sugerir las características ecológicas de las especies, teniendo como 
base que los ciervos predominan en el sotobosque, los bóvidos y équidos en llanuras herbáceas y los caprinos en zonas montañosas.

El conjunto de arte paleolítico al aire libre de Domingo García debe valorarse por su entidad, en el ámbito de otros descubrimientos recientes - Siega Verde (Salamanca) y del valle de Foz Côa (Portugal)- y en el contexto del interior peninsular, lejos, por tanto, de las regiones clásicas del arte paleolítico en el área francocantábrica.

Con las debidas reservas en cuanto a su inclusión dentro de los límites geográficos propuestos, no puede dejar de hacerse alusión a la estación portuguesa de Mazouco, donde a partir de 1981 se dieron a conocer los grabados de un caballo completo y otras dos representaciones indeterminadas (Jorge, S.O., et alii, 1981 y 1982), anunciándose en su ejecución la técnica de piqueteado, que más tarde se haría común en el resto de hallazgos de grabados de esta época al aire libre. Durante años fueron la única referencia de comparación existente para el primer gran caballo descubierto en Domingo García.

Cronológicamente, la estación ha sido situada en un horizonte cultural magdaleniense (Jorge, V.O., 1987), a partir del concepto de santuario monotemático (Jordá, F., 1983), aunque existen opiniones en contra que, desde criterios puramente estilísticos, prefieren referirse nuevamente a ese momento de transición entre los Estilos III y IV de Leroi-Gourhan (Balbín, R. de, y Alcolea, J.J., 1994), opinión que en algún momento fue considerada igualmente por los autores del descubrimiento (Jorge, S.O., et alii, 1981; 1982).

Desde 1989, el descubrimiento de un importante conjunto de grabados en los afloramientos de esquistos de Siega Verde (Salamanca) fue el punto de arranque del cambio en la concepción de las características y personalidad del arte paleolítico del interior peninsular, y obligada referencia para los hallazgos posteriores.

Sus figuras se grabaron mayoritariamente mediante piqueteado, documentándose también la incisión muy fina, de tipo filiforme, la abrasión sobre piqueteado previo y, por último, el piqueteado sobre incisión fina. Entre sus representaciones se observa el predominio de caballos y bóvidos sobre un conjunto de figuras en el que es posible identificar cérvidos y caprinos y una presencia minoritaria de Megaceros, rinoceronte, cánidos y felinos que, a falta del estudio definitivo del conjunto, hay que aceptar con ciertas reservas.

Los convencionalismos estilísticos y formales de las figuras son bastante homogéneos en la totalidad de las representaciones, apuntándose 
ciertos rasgos de arcaismo en los grabados de équidos y sus despieces internos, crineras en doble línea, extremidades inacabadas, etc., así como en el caso de los bóvidos, que comparten con los anteriores su mayoritaria ejecución mediante la técnica del piqueteado.

Cérvidos y caprinos, realizados mediante incisión directa, presentan unas características más avanzadas que las anteriores especies, hecho que choca a los responsables de la investigación de este yacimiento por la infraposición de la mayoría de estos grabados a los anteriores.

De nuevo, la cronología propuesta a partir de criterios estilísticos nos lleva a la ya repetida fase de transición entre los Estilos III y IV de A. LeroiGourhan, siendo perfectamente paralelizable el conjunto con los de Mazouco, Domingo García y Foz Côa, y encuadrable, como ellos, entre el Solutrense Final y el Magdaleniense (Balbín, R. de, et alii, 1991; Balbín, R. de, et alii, 1992; Balbín, R. de, y Alcolea, J.J., 1994).

La última incorporación a este repertorio de yacimientos al aire libre, el conjunto portugués de Foz Côa (Zilhao, J., 1997) polémico por cuestiones que nada han tenido que ver con discusiones sobre fases culturales o cronología, presenta unas características similares a las que hemos descrito para Siega Verde, yacimiento con el que comparte además zona geográfica, ya que ambos se encuentran muy próximos.

La repartición de las estaciones paleolíticas conocidas actualmente, referidas tanto a yacimientos con ocupación o con arte rupestre, muestra una concentración a lo largo de los principales cursos de agua, mostrando la existencia de tres grupos bien diferenciados sobre afloramientos de esquisto de la llamada formación de Desejosa. En la zona media del valle del Côa encontramos los conjuntos de Quinta da Barca/Penascosa y a unos tres kilómetros aguas abajo comienza el área que se ha denominado como Cañón Terminal y que comprende los estaciones de Ribera dos Piscos, Fariseu, Vale Figueira, Canada do Inferno, Rego da Vide, Canada do Amendoal, Vale Moinhos, Broeira, Vale de Cabroes, etc.

Así pues, en el valle de Côa y barrancos adyacentes de la margen izquierda del río Duero se conocen un total de 22 conjuntos con grabados, de las cuales quince contienen arte paleolítico. En este último grupo el número de rocas con incisiones asciende a 194. Si tenemos en cuenta que la parte inferior del curso del Côa actualmente está inundada, en el valle contamos con un mínimo de 150 paneles con grabados. La media de representaciones de los paneles ya estudiados oscila entre los siete de Canada do Inferno y los ocho de Penascosa, con lo cual la estimación mínima de representaciones de este área supera el millar de figuras. 
Las especies mejor representadas en el repertorio artístico de Foz Côa son los bóvidos, caballos, caprinos y cérvidos. La ausencia de representaciones de taxones de clima frío, como las que se encuentran en las cuevas de la región franco-cantábrica (bisontes, rinocerontes lanudos, renos o mamuts entre otros), es normal en el caso del valle del Côa y el resto de estaciones del sur de la Península lbérica, ya que estas especies nunca vivieron más allá del límite que supone la Cordillera Cantábrica.

Estética y estilísticamente el arte de Côa presenta una especificidad poco común en el arte cuaternario, tal y como puede ser la asociación de dos o tres cabezas sobre el cuerpo de un mismo animal con el objetivo de transmitir una idea de movimiento. En otros casos, el artista representó la torsión del cuello volviéndose hacia atrás, convención que únicamente se aprecia sobre representaciones de caprinos, cérvidos y en menor medida sobre bóvidos. Esta especificidad en las representaciones no se ha identificado en ningún otro yacimiento con arte rupestre paleolítico al aire libre y podría considerarse como un marcador regional con un importante significado cultural, étnico y cronológico, que sin duda provocará la revisión de nuestros conocimientos sobre el arte paleolítico europeo.

La cronología que actualmente se maneja ha sufrido muchos avatares y controversias, al igual que el resto del conjunto. Inicialmente, a través de dataciones poco fiables metodológicamente, se obtuvieron unas fechas holocenas. Sin embargo, recientemente se ha aplicado un método muy específico como es el del $\mathrm{Cloro}_{36}$, que ha proporcionado una cronología cuya antigüedad se debe de corresponder con edades máximas superiores a los 20.000 años B.P.

El ciclo artístico de este conjunto se desarrolla a lo largo de las diferentes etapas del Paleolítico Superior, es decir durante unos 15.000 años. De este modo, el intervalo de tiempo entre las primeras y las últimas representaciones es muy largo, existiendo diferencias de coloración en la patina de algunas de las superposiciones, lo cual tiene una significación cronológica de capital importancia que se ve reafirmada por el análisis estratigráfico y estilístico de la representaciones.

En definitiva, el resumen que acabamos de exponer explicita claramente una serie de características del arte paleolítico de la Meseta que, ante el vuelco que ha dado la concepción de éste en los últimos años, debemos tomar con las debidas precauciones y referirnos al estado actual de la investigación, evitando por el momento intentar cualquier tipo de fijación de características generales o rasgos definitorios, habida cuenta de que nos encontramos en franco proceso de revisión de todo lo que hasta el momento se había afirmado sobre este particular. 
Sí es cierto, por otra parte, que las estaciones artísticas consideradas comparten una serie de rasgos comunes que parecen conformar un panorama homogéneo en su definición. Comienzan las coincidencias en la valoración cronológica que la mayor parte de los investigadores hacen de los yacimientos conocidos, considerando momentos comprendidos, desde el punto de vista estilístico, en las fases de desarrollo de los Estilos III y IV de Leroi-Gourhan y, más concretamente, en ese momento considerado de transición entre ambos, en el que se hace patente la presencia de figuras resueltas con convencionalismos arcaicos junto a otras que incluyen las novedades encuadradas en el estilo más reciente.

Como primer rasgo común al conjunto artístico meseteño, habría que referirse al predominio del grabado sobre la pintura, absoluto en el caso de las manifestaciones al aire libre, por otro lado lógico, y que se observa también en los casos en que grabado y pintura conviven en un mismo espacio, si exceptuamos la cueva de Maltravieso, en la que adquieren un protagonismo especial las representaciones pictóricas. Estas últimas aparecen con exclusividad en Ojo Guareña, El Niño y El Reno.

Cabría situar el punto de arranque en las figuras grabadas de la cueva de La Griega, considerada como la más antigua de las estaciones artísticas de la Meseta (Balbín, R. de, y Alcolea, J.J., 1994) a partir del escaso desarrollo de los convencionalismos que, por otra parte, se ajustan perfectamente a las características que definen el Estilo III (Leroi-Gourhan, A., 1965). Compartiría este primer estadio el conjunto cacereño de Maltravieso, a falta de una datación cronológica más precisa.

En la mayoría de las ocasiones, ya se trate de cuevas o de yacimientos al aire libre, puede observarse el predominio que caballos, principalmente, $y$, a continuación, bóvidos y cérvidos, ostentan sobre otras especies animales, relegadas en algunos casos a presencias meramente testimoniales ( $\mathrm{Me}$ gaceros, rinocerontes, etc.), aunque la identificación de algunas de estas especies, digamos, típicamente paleolíticas, no sea lo suficientemente clara en algunos casos y parezca forzada la clasificación morfológica.

Por último, es preciso referirse a la gran homogeneidad, en el estado actual de nuestros conocimientos y ante las áreas conocidas, de los conjuntos de grabados al aire libre en los que se encuadra el segoviano de Domingo García. Tanto en lo que se refiere a localización, en las proximidades de cauces fluviales o humedaies, como en lo que se refiere a elección del soporte, fauna representada, técnicas o estilo, muestran una larga serie de coincidencias que permiten indicar un horizonte común, avalado por las referencias cronológicas antes citadas que señalan una etapa también común dentro de la transición entre los Estilos III y IV. 
No podemos dejar de mencionar una coincidencia más entre todos ellos, como es la falta absoluta de referencias arqueológicas que permitieran adoptar criterios más fiables en cuanto a la atribución cultural de los grabados. A falta de ellas, su encuadre cronológico y cultural debe seguir haciéndose por medio de criterios exclusivamente estilísticos, con el empleo de sistemas que, sin duda válidos en las grandes zonas artísticas francocantábricas, hemos visto ya que presentan abundantes lagunas para el estudio de un tipo de representaciones artísticas recientemente incorporadas al panorama global del arte paleolítico y cuyo estudio, a la luz de dichos métodos, tropieza frecuentemente con problemas difícilmente solucionables.

\section{CONSIDERACIONES FINALES}

De todo lo expuesto hasta el momento se deduce la escasez de datos con los que contamos en la actualidad para valorar el poblamiento de la Meseta durante el Paleolítico Superior. Además, esta información procede, en general, de estudios preliminares a partir de hallazgos recientes o de antiguas excavaciones carentes del suficiente rigor metodológico. Son, por tanto, limitadísimos los datos paleoambientales, paleoeconómicos o radiocarbónicos, y están totalmente ausentes los estudios interdisciplinares, imprescindibles hoy en día para abordar seriamente cualquier estudio de carácter general.

No obstante hay que reconocer, también, que el Paleolítico y más aún el Paleolítico Superior del interior peninsular ha sufrido un especial desinterés por parte de las Universidades castellanas y otros centros de investigación como los museos. Recordemos que hasta hace quince años sólo se conocían algunas cuevas aisladas con manifestaciones de arte rupestre, descubiertas a principios de siglo.

Otro motivo que, posiblemente, ha contribuido al desconocimiento del Paleolítico Superior es la escasa presencia de cavidades en este área, ya que los afloramientos de calizas y areniscas se localizan en el sector occidental de la Meseta y en las estribaciones de los sistemas montañosos. Es muy probable, pues, que el hombre como en etapas anteriores (Paleolítico Inferior o Medio) se estableciera al aire libre. Estos sitios son muy difíciles de reconocer en una prospección, no sólo por la complejidad de su identificación a primera vista, sino porque es muy posible que gran parte de ellos hayan desaparecido por procesos erosivos naturales, o bien estén cubiertos por depósitos sedimentarios de varios metros de potencia. 
Sin embargo, estos últimos años y como ya hemos mencionado antes, se han producido una serie de novedades importantes. Esto supone un importante logro, más aún si se tienen en cuenta las dificultades planteadas por las Administraciones autonómicas para llevar a cabo este tipo de labor. (Es obvio que la actuación de las autonomías durante estos últimos años, que ya empiezan a ser numerosos, ha producido un importante frenazo en estos trabajos de investigación.) Los hallazgos se han incrementado y, además, se ha ampliado el carácter de los yacimientos conocidos. Así, junto a cuevas y abrigos se han dado a conocer asentamientos al aire libre con niveles de ocupación y, además, de las cuevas decoradas (o santuarios) ahora sabemos de la existencia de estaciones rupestres al exterior.

El hecho de que casi todos los yacimientos que se han localizado se encuadren dentro de las últimas etapas del Paleolítico Superior (Magdaleniense-Solutrense) no implica que no existan ocupaciones anteriores. Es muy posible que debido a la baja demografía de las etapas iniciales del Paleolítico Superior el número de yacimientos que podemos encontrar sea estadísticamente menor, pero esto no necesariamente demuestra que la Meseta estuviera deshabitada entre el 35.000 y el 18.000 B.P. Hay que esperar a tener un mayor volumen del registro arqueológico para una mejor valoración de esta hipótesis.

Salvo algunas referencias antiguas que nos hablan de la presencia de Auriñaciense o Gravetiense en las cuevas leonesas (Neira, A., y Mallo, F., 1990), e incluso de la presencia de Chatelperroniense en una terraza del Pisuerga, difíciles de comprobar en la actualidad, parece que la Meseta no llegó a ocuparse al menos de manera generalizada hasta el interestadio Würm III-IV. Los primeros y escasos indicios de poblamiento se remontan al Solutrense, evidenciado en la cuenca del Tajo, en Peña Capón y el Sotillo, y en el valle del Segura, en el abrigo del Palomar. Sólo se conocen algunos elementos industriales que, en principio, sugieren estrechas relaciones con la vertiente mediterránea.

A continuación, los primeros vestigios del Magdaleniense han quedado atestiguados también en el valle del Tajo, en Jarama II, cuya ocupación ha sido atribuida al Magdaleniense Inferior. Otro sitio encuadrable en estos primeros momentos del Magdaleniense podría ser el abrigo de Buendía, aunque creemos conveniente esperar a la excavación para precisar mejor su cronología. En cualquier caso este poblamiento se hace más evidente al final del Tardiglaciar e inicios del Holoceno, momento al que se atribuyen la mayoría de los yacimientos conocidos en la Meseta hasta el momento. Este hecho no parece estar relacionado con la mejoría climática 
acaecido entonces, sino muy posiblemente, y como ocurre en otras áreas, con el aumento demográfico que parece producirse a partir del Tardiglaciar y que conlleva la necesidad de buscar nuevas áreas de explotación ocupándose así la Meseta. Éste, justificaría una mayor intensidad de ocupación que se traduce en un importante incremento de los asentamientos del Magdaleniense Superior-Final e inicios del Epipaleolítico: La Uña y El Espertín (León), El Níspero (Burgos), la Dehesa (Salamanca), Estebanvela (Segovia), Verdelpino (Cuenca) y el Molino del Vadico (Albacete), entre otros.

En general, la mayor parte de los yacimientos que conocemos en la actualidad no parecen corresponder a ocupaciones de larga duración, ya que son abrigos pequeños con niveles de escasa potencia y en muchos casos únicos. Esto parece indicarnos, como ya han sugerido otros autores (Corchón, Mås., 1988-1989), ocupaciones esporádicas, durante períodos relativamente cortos. Algunos de estos yacimientos, como ocurre con los de León y Burgos, tienen una clara relación con la cornisa Cantábrica, debido muy posiblemente a su proximidad, mientras que los de la Meseta Sur, como Buendía, Verdelpino o los de la sierra de Alcázar, presentan un mayor paralelismo con el litoral mediterráneo. Pero éste es un tema en el que sólo futuras investigaciones y un mayor registro arqueológico contribuirá a esclarecer.

\section{BLBLIOGRAFIA}

Adán Álvarez, G., y Jordá Pardo, J.F. (1989): Industrias óseas del Paleolítico y Postpaleolítico Pirenaico en relación con los nuevos hallazgos del Jarama II (Guadalajara). Espacio Tiempo y Forma Serie I, Prehistoria y Arqueología (Madrid), vol. 2, págs. 109-130.

Adán Álvarez, G.; García Valero, M.A.; Jordá Pardo, J.F., y Sánchez Chillón, B. (1989): Jarama II, nouveau gisement magdalénien avec art mobilier de la «Meseta Castellana», Guadalajara, Espagne. Préhistoire Ariégoise, Bulletin de la Societé Préhistorique Ariège-Pyrénées (Foix), vol. XLIV, págs. 97-120, 13 figuras.

Alcolea González, J.J.; Garcia Valero, M.A., y Alcaina Muñoz, M.A. (1995): El poblamiento prehistórico antiguo en el sector suroriental del Sistema Central: Investigaciones en el valle alto del Sorbe (Guadalajara). Raña (Sevilla), núm. 19, $2^{\circ}$ semestre, págs. 37-40.

Alcolea González, J.J.; Balbín BerhmanN, R. DE; Garcia Valero, M.A., y Cruz Naimi, L.A. (1995): La cueva del Turismo (Tamajón, Guadalajara): un nuevo yacimiento rupestre paleolítico en la Meseta castellana. Arqueología en Guadalajara. Patrimonio Histórico Arqueológico de CastillaLa Mancha (Toledo), núm. 12, págs. 127-136, 7 figs.

Alcolea González, J.J.; Balbín Berhmann, R. de; García Valero, M.A., y Jiménez Sanz, P.J. (1997): Nouvelles découvertes d'art rupestre Paléolithique dans le centre de la Péninsule Ibérique: la cueva del Reno (Valdesotos, Guadalajara). L'Anthropologie (París), vol. Cl, págs. 144-163, 23 figuras.

Almagro BASCH, M. (1960): Las pinturas rupestres cuaternarias de la cueva de Maltravieso en Cáceres. Revista de Archivos Bibliotecas y Museos (Madrid) tomo LXVIII, núm.2, págs. 665 707.

Almagro Basch, M. (1969): Las pinturas rupestres de la cueva de Maltravieso, en Cáceres, Guía del visitante. Ministerio de Educación y Ciencia (Madrid), 63 págs., XIV láminas. 
Almagro Gorbea, M. (1971): La cueva del Niño (Albacete) y la cueva de la Griega (Segovia). Dos yacimientos de arte rupestre recientemente descubiertos en la Península lbérica. Trabajos de Prehistoria (Madrid), vol. 28, págs. 9-62, X láminas.

Almagro Gorbea, M. (1972): Descubrimiento de una cueva con arte rupestre paleolítico en la provincia de Albacete. Santander Symposium, Actas del Symposium Internacional de Arte Prehistórico, Santander, págs. 475-498.

Balbin Berhmann, R.de; Moure Romanillo, J.A.; Ripoll Perelló, E. (1982): Grabados esquemáticos de la Comarca de Santa María de Nieva (Segovia). Coloquio Internacional sobre el Arte Rupestre Esquemático de la Península lbérica, Salamanca, 1982, Resumen de comunicaciones, págs. 8-9.

Balbin Berhmann, R. DE; Moure Romanillo, J.A. (1988): «El arte rupestre en Domingo García (Segovia)", Revista de Arqueología (Madrid), núm. 87, págs. 16-24.

Balbin Berhmann, R. de; Alcolea González, J.J., Santonja Pérez, M., y Pérez Martin, R. (1991): Siega Verde (Salamanca). Yacimiento artístico paleolítico al aire libre. Del Paleolítico a la Historia. Museo de Salamanca (Salamanca), pág. 33-48, 12 figs.

Balbin Berhimann, R. DE, y Alcolea González, J.J. (1992): La grotte de Los Casares, et l'art paléolithique de la Meseta espagnole. L'Anthropologie (París), vol. 96, págs. 397-452.

Balbin Berhmann, R. DE, y Alcolea GonzÁlez, J.J. (1994): Arte Paleolítico de la Meseta Española. Complutum (Madrid), vol. 5, págs. 97-138, 14 figuras y XV cuadros.

Balbin Berhmann, R. de; Alcolea González, J.J., y Santonja Pérez, M. (1994): Siega Verde y el arte rupestre paleolítico al aire libre. $6^{\circ}$ Coloquio Hispano-Ruso de Historia. Fundación Cultural Banesto (Madrid), págs. 5-19, 7 figs. y $\vee$ láminas.

Balbin Berhmann, R. de; Alcolea González, J.J., y Santonja Pérez, M. (1995): El yacimiento rupestre paleolítico al aire libre de Siega Verde (Salamanca, España): una visión de conjunto. Primer Congreso de Arqueología Peninsular, Sociedade Portuguesa de Antropologia e Etnologia (Porto), vol. 35/3, págs. 73-102, 12 fig. y Vill láms.

Balbin Berhmann, R. DE (1995): L'art paléolithique à l'air libre de la vallé du Douro. Archéología (París), junio, núm. 313, págs. 34-41

Balbin Berhimann, R. de; Alcolea González, J.J., y Santonja Pérez, M. (1996): Siega Verde. Un art rupestre paléolithique à l'air libre dans la vallée du Douro. Dossiers d'Archeologie (París), diciembre 1995-enero 1996, núm. 209, págs. 98-105.

Bernaldo de Quirós Guidotti, F., y Neira Campos, A. (1992): Mountains occupation sites in the Cantabrian range (Spain). Preistoria Alpina (Trento), vol. 28, núm. 2, págs. 49-58.

BreulL, H. (1920): Miscelanea d'art rupestre. Cueva del Reguerillo près Torrelaguna. Madrid. Boletín de la Real Sociedad Española de Historia Natural (Madrid), págs. 869-870.

Breull, H. (1933): Les peintures rupestres schématiques de la Penínsule lbérique. Au Nord du Tage. Tome I. IV volúmenes. Editorial Lagny (París), 100 págs., 39 figs. y XXIV láminas.

BreulL, H., y Obermaler, H. (1913): Institut de Paléontologie Humaine. Travaux executés en 1912. L'Anthropologie (París), tomo XXIV, págs. 1-16.

Broglio, A. (1996): Guide Archeologiche. Preistoria e Protoistoria in Italia. 4. Paleolítico, Mesolítico e Neolítico dell'ttalia nord-orientale. A.B.A.C.O. Edizioni (Turín), 267 págs.

Cabré Aguilo, J. (1934): Las cuevas de Los Casares y de La Hoz. Archivo Español de Arte y Arqueología (Madrid), núm. 30, págs. 225-254.

CACHO QuesadA, C., y PÉREZ MARín, S. (1995): El Magdaleniense de la Meseta y sus relaciones con el Mediterráneo español: el Abrigo de Buendía (Cuenca). Colloqui «El mon Mediterrani despés del Pleniglacial (18.000-12.000 B.P.)", Celebrado en Bañolas (Gerona) Serie Monogràfica, vol. 17. Museu d'Arqueología de Catalunya (Girona).

CORCHÓN GONZÁLEZ, M. S. (1989): Datos sobre el Epipaleolítico en la Meseta Norte: la cueva del Níspero (Burgos). Zephyrus (Salamanca), vol. XLI-XLI, págs. 83-100.

CóRDOBA DE OYA, B., y VEGA TOSCANO, L.G. (1985): El Paleolítico en la sierra del Segura: proyecto de investigación. Actas del $1^{\circ}$ Congreso de Historia de Castilla la Mancha (Toledo), tomo II, págs. $79-85$.

CÓRDOBA DE OYA, B. (1983): Los materiales del abrigo del Molino Vadico. Una aproximación a los problemas del Paleolitico Superior Mediterráneo Occidental. Memoria de Licenciatura inédita. Universidad Complutense. Facutad de Geografía e Historia (Madrid), $\$ 53$ págs. y XXIV láminas.

Couraud, C. (199). L'Art Azilien. Origine-Survivance. XX Supplément à Gallia Préhistoire (París), 319 págs., 50 figs. y 11 láminas.

D' ERRico, F. (1995). L'art gravé azilien. De la téchnique à la signification. XXXI Supplément à Gallia Prehistoire (París), 329 págs. 
FABIÁN ÁlvAREZ, J.F. (1986): La industria lítica del yacimiento del «La Dehesa» en el Tejado de Béjar (Salamanca). Una industria de tipología Magdaleniense en la Meseta. Numantia (Valladolid), vol. II, págs. 110-141, 21 figuras.

Fortea Pérez, F.J. (1978): Arte paleolítico del Mediterráneo español, Trabajos de Prehistoria (Madrid), vol. 35 , págs. 99-149, 25 figuras.

Garcia-Soto MATEOS, E. (1983): Grabados antropomorfos de la cueva de Penches (Barcina de Los Montes, Burgos). Algunas precisiones sobre su interpretacion y significado. En Homenaje al Prof. Martín Almagro Basch (Madrid), tomo 1, pág. 301-316.

Glory, A.; Vaultier, M., y Santos, M.F. (1966): La grotte ornée d'Escoural (Portugal). Bulletin de la Societé Préhistorique Française (París), tomo 62, facs. 1, págs. 110-117.

Gómez BArRera, J.A. (1993): Arte rupestre Prehistórico en la Meseta Catellano-Leonesa. Junta de Comunidades de Castilla y León (Valladolid), 263 págs. 149 figuras.

GutiÉRREZ, M. (1917): Paleogeografía en los alrededores de Oña. Asociación para el Progreso de las Ciencias. Congreso Valladolid, tomo VI (Madrid), 1916, págs. 304-318.

Hernández-PACHECo, E. (1917): Los grabados de la cueva de Penches. Memoria núm. 17 de la Comisión de Investigaciones Paleontológicas y Prehistóricas, Madrid, 37 págs.

HERNÁNDEZ-PACHECO, F. (1923): Las arenas voladoras de la provincia de Segovia. Boletín de la Real Sociedad Española de Historia Natural, 23, 5, 211-216. Madrid.

IBERo, J.M. (1923): El Paleolítico en Oña y sus alrededores (Burgos). Razón y. Fe (Madrid), núm. 266, t. 67, fasc. 2, págs. 171-194, 8 figuras.

Jimeno Martinez, A.; Fernández Moreno, J.J.; Gómez Barrera, J.A., y Galindo Ortiz, M.P. (1990): Arte paleolítico en la provincia de Soria: la placa de Villalba. Numantia (Arqueología en Castilla y León) (Valladolid), vol. III, págs. 9-50, 12 figs.

Jimeno Martínez, A.; Fernández Moreno, J.J.; Gómez Barrera, J.A. (1991): La placa paleolítica de Villalba. Revista de Arqueologia (Madrid), núm. 124, págs. 12-17.

Jimeno Martínez, A.; Fernández Moreno, J.J.; Gómez Barrera, J.A. (1995): La plaque Paléolithique de Villalba (Soria, Espagne). L'Anthropologie (París), tomo IC, fasc. 2/3, págs. 325-356, 20 figuras.

JoRdÁ Cerdá, F. (1968-1969): Nuevas representaciones rupestres en Ojo Guareña (Burgos). Zephyrus (Salamanca), vol. XIX-XX, págs. 61-71.

JORDÁ CERDÁ, F. (1970): “Sobre la edad de las pinturas de la Cueva de Maltravieso". XI Congreso Nacional de Arqueología. Mérida, 1968 (Zaragoza), págs. 139-153, 8 figs.

Jordá Pardo, F., y SAnchidrián Torti, J.L. (1992): La Cueva de Maltravieso. Guías Arqueológicas, núm. 22. Editora Regional de Extremadura (Mérida), 1992, 21 págs.

JORDÁ PARDO, J.F. (1988): Investigaciones prehistóricas en el Alto Valle del Jarama (Guadalajara). I Congreso de Historia de Castilla-La Mancha. Toledo, 1985 (Toledo), tomo II, Pueblos y Culturas Prehistóricas y Protohistóricas (1) págs. 111-123.

JoRdá PARDO, J.F. (1993): El poblamiento Paleolítico Prehistórico en el Sector sur oriental del Sistema Central Peninsular (Alto valle del Jarama, Guadalajara). Primer Congreso de Arqueología Peninsular, Sociedade Portuguesa de Antropologia e Etnologia (Porto), vol. 33 (3-4), págs. 99-113.

Jordá Pardo, J.F.; García Valero, M.A.; Adán Álvarez, G. y Sánchez Chillón, B. (1988-1989): Una nueva pieza de arte mueble Magdaleniense: el glotón de la cueva de Jarama II (Valdesotos, Guadalajara). Ars Praehistorica (Barcelona), tomo VII-VIII. págs. 107-122, 2 figuras.

JORDÁ PARDO, J.F., y GARCIA VALERO, M.A. (1989; : Las representaciones de glotón (Gulo gulo L) en el arte Paleolítico pirenaico y un nuevo hallazgo de arte mueble en el Alto Valle del Jarama (Guadalajara). Espacio, Tiempo y Forma, Serie I, Prehistoria y Arqueología (Madrid), vol. II, págs. $89-105,5$ figs.

Jordá Pardo, J. F.; Garcia Valero, M.A.; Pérez Morales, C.; Sánchez-Monge llusá, M.; Estrada Garcia, R.; BENITO, F., y SÁNCHEZ CHILLÓN, B. (1989): Investigaciones prehistóricas del alto valle del Jarama. Revista de Arqueologia (Madrid), núm. 94, págs. 61-62.

JordÁ PARdo, J.F.; ARRIBAs, A., y Díez FERnÁndez-LomanA, C. (1995): El yacimiento cuaternario de la Cueva de los Torrejones (Tamajón, Guadalajera): resultados preliminares. Arqueologia en Guadalajara. Patrimonio Histórico Arqueológico de Castilla-La Mancha (Toledo), núm. 12, págs. 97-123.

Jorge, S.O.; Jorge, V.O.; Almeida, C.A.F. DE; Sanches, M.J., y SoEIRO, M.T. (1982): Descoberta de gravuras rupestres em Mazouco, Freixo de Espada-à-Cinta (Portugal). Zephyrus (Salamanca), vol. XXXIV-XXXV, págs. 65-69.

JoRGE, V.O. (1987): Arte rupestre en Portugal. Revista de Arqueología (Madrid), núm. 76, págs. $10-19$. 
Lerol-Gourhan, A. (1965): La Préhistoire de l'art occidental. Edit. Mazenod (Paris), 482 págs., 802 figs. con láminas y cuadros.

LoRIANA, MARQUÉS DE (1942): Grabados auriñacienses en una cueva de la provincia de Madrid. Archivo Español de Arqueologia (Madrid), núm. 46, págs. 76-78.

Martín Santamaria, E.; Rojo Vega, A., y Moreno Asenjo, M.A. (1986): Hábitat postmusteriense en Mucientes (Valladolid). Numantia (Valladolid), vol. II, págs. 87-100.

MARTínez García, J. (1986-1987): Un grabado paleolítico al aire libre en Piedras Blancas (Escullar, Almería). Ars Praehistorica (Barcelona), tomo V-VI. págs. 49-58, 8 figuras.

MARTinez GaRcia, J. (1992): "Arte paleolítico en Almeria; los primeros documentos". Revista de Arqueología (Madrid), núm. 130, págs. 25-33.

Moure Romanillo, J.A. (1985): El Paleolítico y el Arte Rupestre en Burgos. En Historia de Burgos: 1. Antigüedad, Caja de Ahorros Municipal de Burgos, págs. 83-114.

Moure Romanilio, J.A., y Fernandez Miranda, M. (1977): El abrigo de Verdelpino (Cuenca). Noticia de los trabajos de 1976. Trabajos de Prehistoria (Madrid), vol. 34, págs. 31-83, 10 figs. y 2 gráficos.

Moure Romanillo, J.A. y López García, P. (1979): Los niveles Preneolíticos del abrigo de Verdelpino (Cuenca): XV Congreso Nacional de Arqueología. Lugo 1977 (Zaragoza), págs. 111-124.

Neira Campos, A. y Bernaldo de Quirós GuidotTl, F. (1993): Paleolítico Superior Final de alta montaña en la cordillera cantábrica (Noreste de León). Pyrenae (Barcelona), núm.24, págs. 1722.

Neifa Campos, A., y Mallo fefnández, F. (1990): Análisis estadístico de materiales líticos paleolíticos: «La cueva de la Cantera (Alcedo, León)». Trabajos de Prehistoria (Madrid), vol. 47, págs. 321-338, 1 fig. y 12 tablas.

PÉREZ DE BARRADAS, J. (1919): Nuevos yacimientos paleolíticos de superficie de la provincia de Madrid. Bol. Sociedad Española de Historia Natural (Madrid), vol. XIX, págs. 212-216.

PÉREZ de BARRAdAs, J. (1929): Las investigaciones prehistóricas madrileñas. Su historia e importancia. Boletín del Instituto Geológico y Minero de España, t. XII, 3. ${ }^{a}$ Serie, pp. 5-172.

PÉrEZ DE BARRADAS, J. (1935): Nuevos estudios sobre prehistoria madrileña: La colección Bento. Anuario de Prehistoria Madrileña (Madrid), vol. VI, págs. 3-90.

Pericot Garcia, L., y Fullola Pericot, J.M. (1981): El Solutrense ibérico: revisión y nuevos datos, en Homeje a Lionel Balout. Préhistoire Africaine, Ed. A.P.P., pp. 41-44.

RiPOll LóPEZ, S., y MUNicio GonzÁlez, L. (1992): Las representaciones de estilo paleolítico en el conjunto de Domingo García (Segovia). Espacio, Tiempo y Forma, Serie I, Prehistoria y Arqueología (Madrid), vol. V, págs. 107-138, 21 figuras.

RIPOLL LOPEZ, S., y MUNICIO GONZÁEZ, L.J. (1994): Un grand ensemble d'art rupestre paléolithique de plein air dans la Meseta espagnole. International Newsletter on Rock Art. Bulletin de I'I.N.O.R.A. (Foix, Francia), n. 7, págs. 2-4.

Ripoll López, S.; Municio González, L.; Muñoz ibáñez, J. F.; Pérez Marin, S., y lópez Moreno de REDRojo, J. R. (1994): El Cerro de San Isidro en Domingo García. Nuevos descubrimientos. Revista de Arqueología (Madrid), núm. 157, pág. 12-21.

Ripoll López, S., y Collado Giraldo, H. (1996): Una nueva estación paleolítica en Extremadura. Los grabados de la Cueva de la Mina de Ibor (Castañar de Ibor, Cáceres). Revista de Estudios Extremeños (Badajoz), tomo LII, núm. II, págs. 383-399, 7 figuras.

Ripoll lopez, S.; Collado Giraldo, H.; Ripoll Perelló, E., et alii (en prensa). Maltravieso. El santuario de las manos. Consejería de Cultura y Patrimonio, Dirección General de Patrimonio Cultural de la Junta de Extremadura.

Ripoll López, S.; Ripoll Perelló, E.; Collado Giraldo, H., y L.E.P. (1997): Cueva de Maltravieso. Recuperación y estudio de una singular estación artística del Paleolítico Superior. Revista de Arqueología (Madrid), núm. 193, págs. 6-15, 13 figuras.

Ripoll lópez, S.; Ripoll Perelló, E.; Collado Giraldo, H., Mas Cornellá, y L.E.P. (en prensa): Avance al estudio de la cueva de Maltravieso (Cáceres). El arte rupestre paleolítico en Extremadura. En Jornadas sobre arte rupestre en Extremadura organizadas por la Consejería de Cultura y Patrimonio de la Junta de Extremadura Cáceres 28 y 29 de noviembre de 1996.

Ripoll Perello, E. (1984): Notes de certaines répresentations d'animaux dans l'art Paléolithique de la Péninsule Ibérique. En H.G. Bandi, W. Huber, M. R. Sauter y B. SitTer, edits., La contribution de la zoologie, et de l'ethologie a l'interpretation de l'art des peuples chasseurs préhistoriques. $3^{\text {er }}$ Colloque de la Societé suisse des Sciences Humaines. Sigrisville, 1979, Editions Universitaires de Fribourg, págs. 263-282, 12 figs. 
RIPOLL PERELLó, E. (1991): Proyecto sobre estudio de y documentación de los grabados rupestres de Domingo García. Junta de Castilla León, Dirección General del Patrimonio y Promoción. Informe inédito.

Ripoll Perelló, E., y Grupo Edelweis (1957): Revisión de la cueva de Penches. Crónica del IV Congreso Arqueológico Nacional, Burgos 1955 (A. Beltrán Edit.) (Zaragoza), págs. 57-60, 2 figuras.

SAuvet, G. (1983): Los grabados rupestres prehistóricos de la cueva de La Griega (Pedraza, Segovia). Corpus Artis Rupostris, vol. 1, Palaeolhitica Ars (Salamanca), vol. 2, 30 págs.

SAUVET, G. y S. (1983): Les representations d'équides paléolithiques de la grotte de La Griega ( Pedraza, Segovia). A propos d'une nouvelle découverte. Ars Praehistorica (Barcelona), vol. II, págs. $49-59,8$ figuras.

SAUVET, G. (1985): Les gravures paléolithiques de la Griega (Ségovie, Espagne). Préhistoire Ariégoise, Bulletin de la Societé Préhistorique Ariège-Pyrénéss, vol. XXX, págs. 141-167.

Sauvet, G. (1986): La cueva de La Griega. Nuevos grabados paleolíticos en la Meseta. Revista de Arqueología (Madrid), núm. 66, págs, 6-15.

THEVEnIN, A. (1983) Les galets gravés, et peints de l'abri de Rochedane (Doubs) et le probème de l'art azilien. Gallia Préhistoire (París), vol. 26, núm. 1, págs. 139-188.

URRIBARRi Angulo, J.L. (1969): Las pinturas rupestres de Ojo Guareña, Burgos. Abhandlungen (Alemania), vol. V.

URRIBARRI ANGULO, J.L., y Lız, C. (1973): El arte rupestre de Ojo Guareña. La Cueva de Kaite. Trabajos de Prehistoria (Madrid), vol. 30, págs. 69-120.

Utrilla Miranda, P. (1995): El valle del Ebro durante el Tardiglaciar y comienzos del Holoceno. Las relaciones con el Magdeleniense Cantábrico, En MouRE, A. y GonzÁLEz SAINz, C. (eds.) El final del Paleolítico Superior Cantábrico: transformaciones ambientales y culturales durante el Tardiglaciar y comienzos del Holoceno en la Región Cantábrica (Santander), págs. 281-311.

Utrilla Miranda, P., y Mazo, C. (1994): El Solutrense en el valle del Ebro. Monográfico sobre el Solutrense en la Península lbérica, Férvedes (Villalba, Lugo), vol. I, págs. 89-104, 7 figuras.

Utrilla Miranda, P., y Mazo, C. (1996): El arte mueble sobre soporte lítico de la cueva de Abauntz, su aportación a los estilos del Magdaleniense tardio. Complutum (Madrid), Extra 6 (1), págs. $41-62,15$ figuras.

Vega Toscano, L.G. (1993): Excavaciones en el Molino del Vadico (Yeste). El final del Paleolítico e inicios del Neolítico en la Sierra del Segura. Jornadas de Arqueología Albacetense de la Universidad Autónoma de Madrid. (Madrid), págs. 3-32, 1 fig. y II lams.

Villaverde Bonilla, V. (1994): Arte Paleolitico de la Cova del Parpalló. Estudio de la colección de plaquetas y cantos grabados y pintados. Servei de Investigació Prehistòrica Diputació de Valencia, 2 tomos, vol. I: 404 págs., 50 figs. y LX) (V láminas. vol. ll: inventario y 316 figuras.

Zı..HAO, J. (Coordinador) (1997): Arte Rupestre e Pré-História do Vale do Côa. Trabalhos de $1995-$ 1996. Relatorio cientifico ao Governo da República Portuguesa elaborado nos termos da resoluçao do Conselho de Ministros núm. 4/96, de 17 de Janeiro. Ministério da Cultura (Lisboa), 453 páginas, con figuras y laminas. 